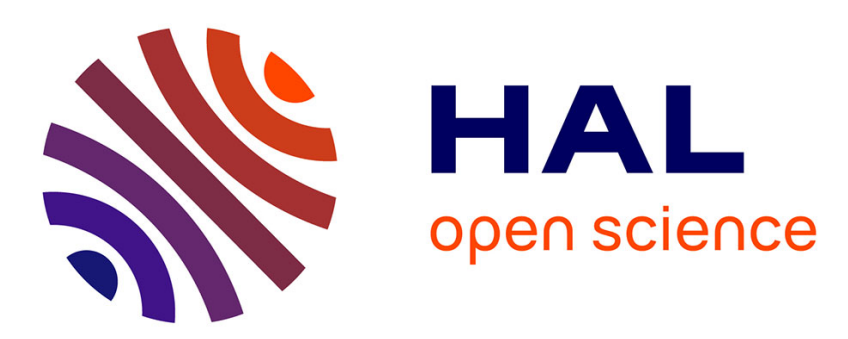

\title{
Defining and characterizing urban boundaries: A fractal analysis of theoretical cities and Belgian cities
}

Cécile Tannier, Isabelle Thomas

\section{To cite this version:}

Cécile Tannier, Isabelle Thomas. Defining and characterizing urban boundaries: A fractal analysis of theoretical cities and Belgian cities. Computers, Environment and Urban Systems, 2013, 41, pp.234248. 10.1016/j.compenvurbsys.2013.07.003 . hal-00858202

\section{HAL Id: hal-00858202 https://hal.science/hal-00858202}

Submitted on 14 Jun 2021

HAL is a multi-disciplinary open access archive for the deposit and dissemination of scientific research documents, whether they are published or not. The documents may come from teaching and research institutions in France or abroad, or from public or private research centers.
L'archive ouverte pluridisciplinaire HAL, est destinée au dépôt et à la diffusion de documents scientifiques de niveau recherche, publiés ou non, émanant des établissements d'enseignement et de recherche français ou étrangers, des laboratoires publics ou privés. 
TANNIER C., THOMAS I. (2013), Defining and characterizing urban boundaries: A fractal analysis of theoretical cities and Belgian cities, Computers, environment and urban systems, vol. 41, pp. 234-248.

\title{
Defining and characterizing urban boundaries: A fractal analysis of theoretical cities and Belgian cities
}

Cécile Tannier \& Isabelle Thomas

\begin{abstract}
In this paper we extract the morphological boundaries of urban agglomerations and characterize boundary shapes using eight fractal and nonfractal spatial indexes. Analyses were first performed on six archetypal theoretical cities, and then on Belgium's 18 largest towns. The results show that: (1) the relationship between the shape of the urban boundary (fractal dimension, dendricity, and compactness) and the built morphology within the urban agglomeration (fractal dimension, proportion of buildings close to the urban boundary) is not straightforward; (2) each city is a unique combination of the morphological characteristics considered here; (3) due to their different morphological characteristics, the planning potential of Flemish and Walloon cities seems to be very different.
\end{abstract}

\section{INTRODUCTION}

Identifying the advantages and disadvantages of various city shapes for different planning goals (e.g. preserving ecological connectivity, improving access to urban and rural amenities, ensuring a good ventilation of city center, etc.) requires - among other things the associated urban built patterns to be more accurately described and characterized. Describing and characterizing city shapes has already generated a wealth of publications: numerous methods have been proposed to identify different types of urban patterns; many spatial indexes have been proposed to measure urban sprawl; and a number of publications have shown the value of measuring fractal dimensions for characterizing city 
shapes.

In this paper, we look to contribute to this field of research by exploring the multiscale morphological properties of built patterns in more depth. We use a fractal methodology for the morphological delineation of urban agglomerations, and fractal and nonfractal indexes to characterize them. Analyses are supported by a systematic comparison of realworld cities with theoretical cities. By doing this, we aim to show that using both fractal and nonfractal measuring methods and comparing results obtained for real world cities and for theoretical cities is fruitful, and opens new perspectives for the use of mathematical tools to support planning decisions.

There is at present no consensus about the best way of delineating urban agglomerations, either in terms of methods, or in terms of criteria or thresholds (see Dujardin, Thomas, \& Tulkens, 2007; Ferreira, Condessa, Castro e Almeida, \& Pinto, 2010 for examples and reviews). Identifying urban boundaries involves analyzing both the functional and the morphological aspects of the human settlement system. Here we have adopted a morphological approach because the criteria used are often more objective and more easily comparable (Weber, 2001). This is especially valuable for making international comparisons and/or for modeling urban growth (Batty \& Longley, 1986).

The morphological delineation of an urban agglomeration is often based on typologies of elementary spatial units. A contiguity constraint and/or a distance threshold are often added to ensure that the spatial units forming the morphological agglomeration make up a contiguous set (Weber, 2001). However, the relevance of a predefined distance threshold is questionable when analyzing urban fringes where the spacing of neighboring buildings varies considerably, as is common in Europe (Chaudhry \& Mackaness, 2008). In order to overcome this difficulty, at least three methods can currently be found in the literature. The first is the city clustering algorithm (CCA) proposed by Rozenfeld et al. (2008), the second derives "natural cities" by clustering street nodes (Jiang \& Jia, 2011), and the third is a fractal-based method proposed by Tannier, Thomas, Vuidel, \& Frankhauser (2011). The present paper is based on this last method, which avoids using any predefined distance threshold between buildings to detect discontinuities in space across scales. With 
this methodology, cities characterized by similar global densities may exhibit different distance thresholds.

In practice, the method developed by Tannier et al. (2011) is applied here for mapping the urban boundaries of six theoretical urban patterns as well as Belgium's 18 largest cities. The rank-size distribution of the delineated built clusters is then analyzed to identify a morphological agglomeration within each urban pattern. We further characterize the shape of the morphological agglomeration using eight morphological (fractal and nonfractal) indexes. This allows us to compare theoretical and Belgian city shapes and to analyze their diversity. In doing so, we address the following planning questions: is the urban boundary clear-cut (as recommended by a compact city policy), or is it characterized by a fuzzier and more gradual limit? Can this urban/rural boundary be easily and unequivocally characterized and how? How do city shapes vary within Belgium where land use policy is subnational and not national?

Figure 1: A synthetic view of the methodology used

\section{Delineate the morphological agglomeration}

1. Data: build map

Step-by-step dilation

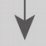

2. Make log-log plot of the number of built clusters at each dilation step

3. Compute distance threshold to delineating the urban boundaries

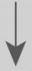

4. Map the urban boundaries

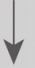

5. Plot the rank-size distribution of the delineated built clusters

6. Identify the largest built cluster(s)

Characterize its form

7. Extract the buildings belonging to the morphological agglomeration

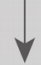

8. Compute the 8 morphological indexes 


\section{METHODOLOGY}

\subsection{Delineating the morphological agglomeration: a fractal approach}

Only very simple data are needed: a vector map (building map) representing buildings in two dimensions (polygons). Any other land uses (e.g. streets, green areas, fields, undeveloped sites) are categorized as non built-up spaces. In the case of theoretical cities (Section 3), built polygons are $10 \times 10 \mathrm{~m}$ squares; this corresponds to the average size of the spatial footprint of an individual residential building in Belgium. In the case of Belgian cities (Section 4), the size of the smallest built polygons is 4 sq meters but most polygons are larger; data were provided by the Land Registry Administration of Belgium. The spatial extent of each urban region is quite large comprising an urban agglomeration (monocentric or polycentric) and its hinterland (i.e. suburban or rural areas under the influence of the urban core).

The method adopted for identifying the morphological agglomeration (noted $M A$ ) in each urban region (noted $U R$ ) is summarized in Figure 1. A step-by-step dilation is applied to each building on the map and polygons merge as they intersect; the number of built clusters is counted after each dilation step and the results are portrayed on a log-log plot, where the $X$-axis represents the width of the dilation buffer and the $Y$-axis the corresponding number of built clusters (Steps 1 and 2, Figure 1). A distance threshold is then identified on the dilation curve (Step 3, Figure 1). It corresponds to the point characterized by the maximum curvature, which measures how far a curve deviates from a straight line at a given point (Lowe, 1989). In order to compute the curvature for each point of the dilation curve, the curve was estimated by a polynomial, the degree of which was chosen using the BIC (Bayesian Information Criterion). The maximum curvature of the dilation curve reveals a major spatial discontinuity across scales. The corresponding distance threshold separates two morphological spatial subsets that are distinct in fractal terms: below that threshold, built elements are organized according to the same spatial logic and belong to the same morphological agglomeration. This further allows us to describe each urban agglomeration using two spatial indexes: the distance threshold at which distances between buildings no longer exhibit the same fractal behavior, and the value of maximum curvature of the dilation curve. Mapping the urban boundaries then 
consists in applying a buffer with a diameter equal to the distance threshold to the building map (Step 4, Figure 1).

All the computations and GIS-based analyses were processed using Morpholim software and the method is described in detail in Tannier et al. (2011).

The map obtained after Step 4 displays the urban boundary of all built clusters, some of them being very large, others very small. On this map, the largest built cluster(s) was (were) identified by visual analysis of the rank-size distribution of all built clusters (Steps 5 and 6, Figure 1). The largest built cluster corresponds to the morphological agglomeration. Sometimes, toward the top of the rank-size distribution, several clusters are almost the same size. In such cases, all the largest clusters are selected and are considered to form the morphological agglomeration.

The rank-size distribution allows different types of built patterns to be identified according to the form of the relation between the size of the built clusters and their rank. For instance, the rank-size distribution may be a straight line; in this case, the distribution strictly obeys a power law: the logarithm of the number of built clusters decreases proportionally to the logarithm of their size. In other cases, the rank-size distribution may vary from a straight line. This occurs in particular when built patterns exhibit a primate cluster.

\subsection{Characterizing the shape of the morphological agglomeration}

Three sets of indexes characterize the shape of the morphological agglomeration (Figure 1, Steps 7 and 8). The first set measures how far the agglomeration differs morphologically from its surrounding (rural) environment (Section 2.2.1), the second (2.2.2) characterizes the shape of the boundary of the morphological agglomeration, and the third set (2.2.3) measures the potential access to urban and rural amenities.

\subsubsection{Urban/rural differences}

In order to explore the extent to which the morphological agglomeration (MA) differs from its hinterland, we measure the fractal dimension of the built surface $D_{s}$ of both the entire urban region $D_{S}(U R)$ and the corresponding morphological agglomeration $D_{S}(M A)$. 
Fractal dimensions enable us to easily distinguish built-up patterns characterized by high diversity in the size of the built clusters and in the distances separating these clusters (fractal dimension close to 1.5) from uniform built-up patterns in which buildings may be either scattered or concentrated (fractal dimension close to 2) (Thomas, Frankhauser, \& De Keersmaecker, 2007). An increase in fractal dimension may result from either the outward spread of a city or a space-filling process (Feng \& Chen, 2010).

Fractal dimensions are calculated here using a box-counting algorithm (Batty \& Longley, 1994; Benguigui, Czamanski, Marinov, \& Portugali, 2000; Benguigui, BlumenfeldLieberthal \& Czamanski, 2006; Feng \& Chen, 2010; Shen, 2002) included in Fractalyse software (Vuidel, Frankhauser, \& Tannier, 2006). The fractal box dimension is consistent with Shannon entropy and is a good measure of spatial uniformity (Feng \& Chen, 2010). Fractalyse computes fractal dimensions from raster data only. Hence each building map has to be rasterized. A very small (4 sq meters) pixel size was selected so as to preserve most of the details of the initial vector data. Fractalyse uses square boxes of increasing size to cover the built pattern (the box side length is doubled from one level of analysis to the next) and the number of boxes containing at least one built pixel is counted. This boxcounting method is very similar to other counting methods, in particular the grid-counting method (Feng \& Chen, 2010). The results are displayed on a log-log plot of the number of occupied boxes ( $Y$-axis) versus box size ( $X$-axis). If a pattern is fractal, the curve that relates the box size to the number of non-empty boxes is a straight line, and the fractal dimension is equal to the slope of the curve.

In practice, the empirical counting curve (log-log plot of the number of occupied boxes at each analysis level) is adjusted by an estimated curve (here a straight line whose slope is the fractal dimension $D$ ) using an OLS regression. The statistical validity of the adjustment is assessed by computing an $R^{2}$ and a $p$-value.

The box-counting algorithm does not provide perfect coverage of an urban pattern. Hence, the number of occupied boxes and the resulting computed fractal dimensions $\left(D_{S}(M A)\right.$ and $\left.D_{S}(U R)\right)$ are approximated. However, given the size of the areas studied here and the high resolution of the building maps, fractal dimensions computed in this 
way do provide a very good characterization of the studied patterns. Estimating the box dimension requires a sufficient number of levels of analysis (i.e. enough jumps in box size). For Belgian cities, the number of levels was 14 or 15, while it varied from 12 to 14 for our theoretical cities. The box-counting algorithm also requires the largest possible range of box sizes (at least three orders of magnitude) (Gonzato, 1998). Our analyses fulfill this requirement. Notice that the maximum box size is, at most, less than half the image size, and it is usually much less.

\subsubsection{The shape of the urban boundary}

A fractal box dimension, noted $D_{B}(M A)$, was computed on the boundary of each morphological agglomeration. It characterizes the lengthening of the boundary as well as its degree of space-filling across scales (Longley \& Batty, 1989). The urban boundary is statistically self-similar for a limited scaling range (Chen, 2011; Tannier \& Pumain, 2005). Considering this, the minimum box size for computing $D_{B}(M A)$ has been set to be just larger than the distance-threshold marking the limit of each morphological agglomeration.

A second index (dendricity index, $\delta$ ) expresses the scaling relationship between the

length and shape of the outline of the morphological agglomeration and the spatial organization of the buildings within the $M A$ :

$$
\delta=2-\left[D_{S}(M A) / D_{B}(M A)\right]
$$

$\delta$-values close to 0 show that the fractality of the boundary (i.e. the diversity in the number and length of line convolutions) is lower than the fractality of the built surface (i.e. the diversity in the number and size of built clusters), while values close to 1 indicate that the boundary is convoluted across scales in the same proportion as the built surface exhibits contrasts across scales. This index is equivalent to the perimeter-area scaling parameter $D_{B} / D_{S}$ used by Imre and Bogaert (2004) and Benguigui et al. (2006). $\delta$-values are sometimes slightly greater than 1 , indicating that $D_{B}(M A)$ is higher than $D_{S}(M A)$. This is explained by the fact that the urban boundary is here not strictly a subset of the built-up surface of the morphological agglomeration. 
A third, intrinsically nonfractal index is also computed for characterizing the overall shape of the morphological agglomeration: the compactness index $(C O)$ :

$$
C O=\left[2(\pi . A)^{1 / 2}\right] / P
$$

based upon the relation $P=2(\pi \cdot A)^{1 / 2}$ for disks (Richardson, 1961). $C O$ tends to 1 for very simple perimeters such as a circle or a square (the perimeter of the shape is rather short compared to its surface area), and to 0 for shapes with very long perimeters compared to their surface areas.

\subsubsection{Location of the buildings with respect to the urban boundary}

The final set of indexes refers to the location of the buildings with respect to the boundary of the morphological agglomeration. $\% B(M A)$ stands for the percentage of buildings in an urban region that belong to the morphological agglomeration. This index can be considered as a proxy for the location of urban amenities. As suggested by Parr (2007), we assume that buildings located within the morphological agglomeration have better access to urban amenities than those located outside.

$\% B-5 m(M A)$ is the percentage of buildings in an urban region that belong to the morphological agglomeration and that are located less than 5 meters from the urban boundary. This index is used as a proxy for assessing the proximity of residents to both urban and rural amenities. It takes into account direct (possibly visual) access to the urban boundary. A similar index $\% B-150 m(M A)$ is computed for a 150 -meter distance threshold, in order to assess proximity to the urban boundary on foot.

\section{THEORETICAL URBAN PATTERNS}

\subsection{Generating patterns}

Six theoretical urban agglomerations were designed . Each of them is a metaphor of a city (concentration of buildings) surrounded by rural settlements (dispersed buildings randomly and fairly uniformly distributed). The six patterns were generated in accordance with classical spatial models of urban organization inspired by theory (see e.g. Bosselman, 2008). Three of the theoretical cities are fractal (Sierpinski Carpet City, 
Fournier Dust City, and Hybrid Carpet City), but the others are not (Compact City, Non Hierarchical Polycentric City, and Dispersed City) (Figure 2).

Figure 2: Six theoretical cities in their rural environments

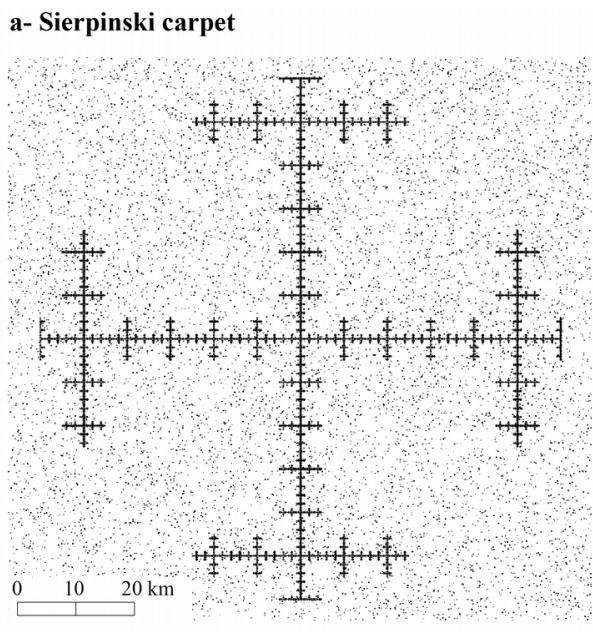

b- Fournier dust

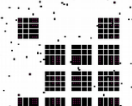

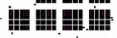

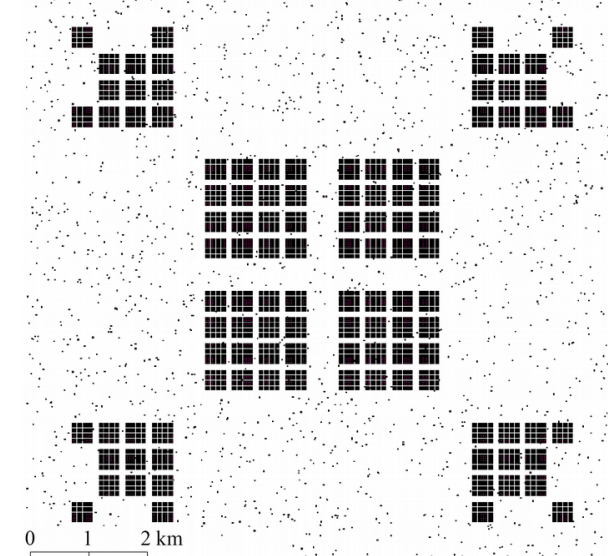

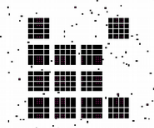

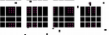

c- Hybrid fractal carpet

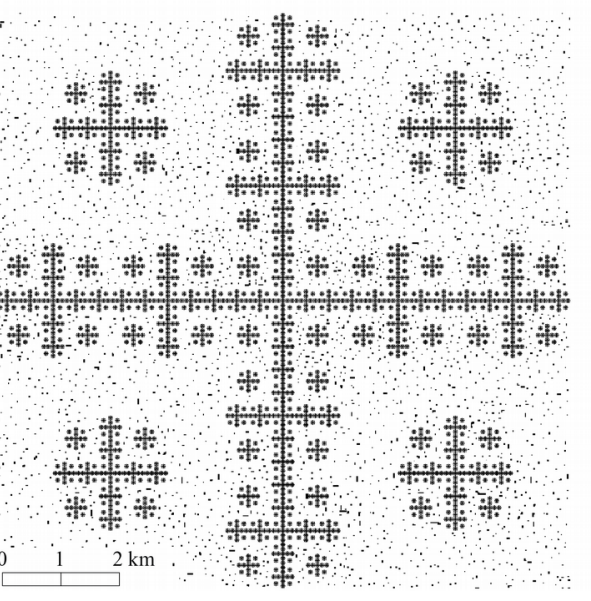

d- Compact city

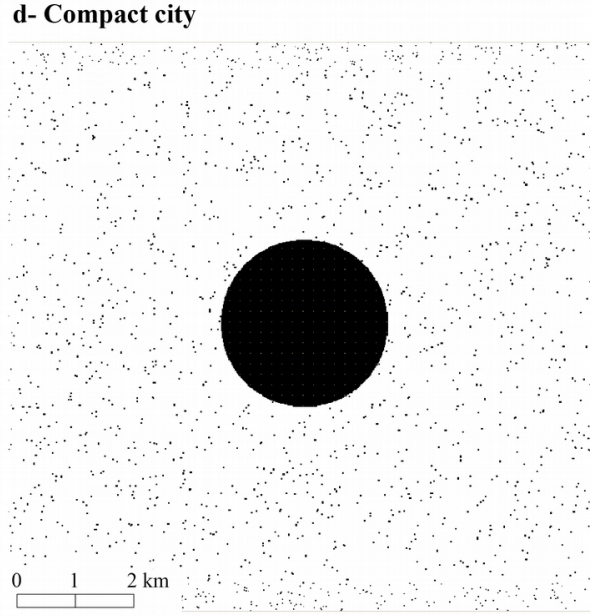

e- Non hierarchical polycentric city

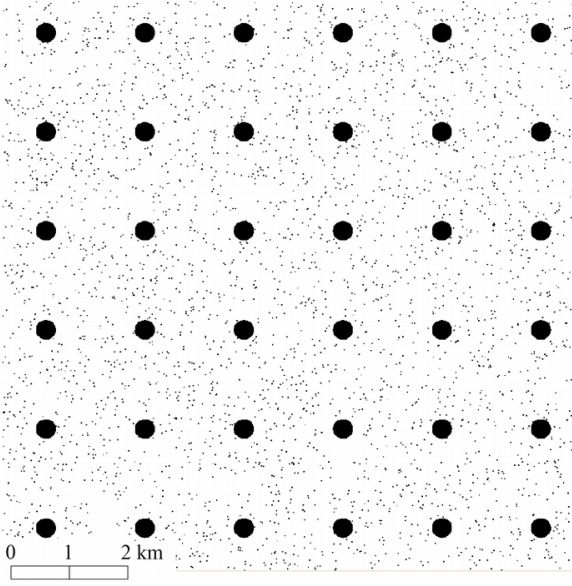

f- Dispersed city

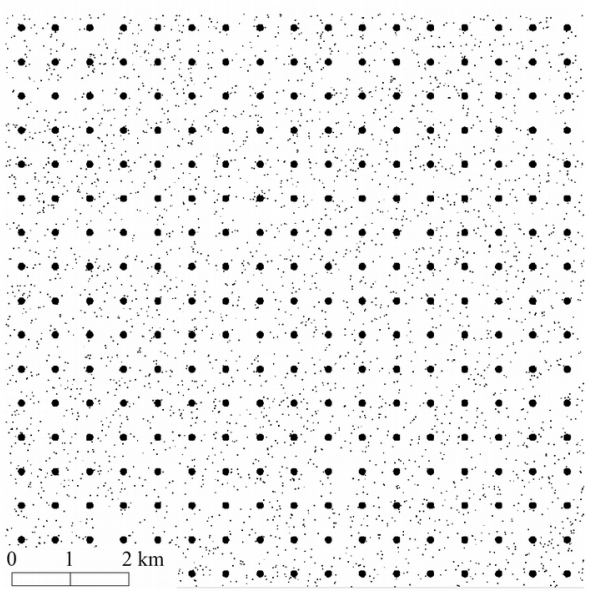


The built-up elements of the Compact City are all concentrated in one central circular settlement. The built elements of the Non Hierarchical Polycentric City are concentrated in 36 equally sized clusters, and those of the Dispersed City are concentrated in 289 smaller but evenly sized clusters. Among the fractal cities, the Fournier Dust is made up of unconnected elements across scales, whereas the Sierpinski Carpet consists of connected elements across scales (Mandelbrot, 1982). European urban areas usually combine features of both Fournier Dust and Sierpinski Carpet with regard to connectivity between buildings (Thomas, Frankhauser, \& Badariotti, 2012); such a combination is represented in the Hybrid Fractal Carpet City.

The size of the theoretical urban regions (i.e. the square window encompassing the theoretical town) is the same in five cases out of six $(10 \times 10 \mathrm{sq} \mathrm{km})$. The Sierpinski carpet is, by definition, a more dilute pattern (around $100 \times 100 \mathrm{sq} \mathrm{km}$ ); this pattern should, however, not be omitted since it has been referred to in many previous analyses (e.g. Batty \& Longley, 1994; Cavailhès, Frankhauser, Peeters, \& Thomas, 2004). The number of buildings in each theoretical city (about 28,000) and the density of rural settlements surrounding the morphological agglomeration (40 buildings per sq $\mathrm{km}$ ) are the same in all our theoretical cities.

\subsection{Delineating the theoretical urban agglomerations}

The urban boundaries were defined using Morpholim software (Table 1). The distance threshold (Column 4, Table 1) refers to the value below which buildings are considered to belong to the same morphological fractal subset. This criterion does not discriminate among the six patterns being studied because each theoretical city is clearly different from its surrounding "rural" environment. This is to be expected in a theoretical context, but will not be the case in real world cities. Column 5 (Table 1) refers to the maximum curvature of the dilation curve. As suggested by Tannier et al. (2011), the absolute value should be considered. The lowest observed value corresponds to the Hybrid Fractal Carpet (2.06), which exhibits the least clear-cut urban boundary within our set of examples. 
Table 1: Extracting the boundary of the morphological agglomerations (MA) within the six theoretical urban regions (UR): basic structural indexes.

\begin{tabular}{|c|c|c|c|c|c|}
\hline $\begin{array}{c}\text { (1) } \\
\text { City type }\end{array}$ & $\begin{array}{l}\text { (2) } \\
\text { Surface of the } \\
\text { UA }\left(\mathrm{km}^{2}\right)\end{array}$ & \begin{tabular}{l}
\multicolumn{1}{c}{ (3) } \\
Number of \\
buildings \\
in UA
\end{tabular} & \begin{tabular}{l}
\multicolumn{1}{c}{$(4)$} \\
Distance \\
threshold \\
(in m)
\end{tabular} & \begin{tabular}{l}
\multicolumn{1}{c}{$(5)$} \\
Curvature \\
(polynomial of \\
$6^{\text {th }}$ degree) \\
\end{tabular} & \begin{tabular}{l}
\multicolumn{1}{c}{$(6)$} \\
Number of \\
primate \\
clusters
\end{tabular} \\
\hline Compact & 100 & 32337 & 75.61 & -2.50 & 1 \\
\hline $\begin{array}{l}\text { Non-hierarchical } \\
\text { polycentric }\end{array}$ & 100 & 32648 & 74.31 & -2.29 & 36 \\
\hline Dispersed & 100 & 31697 & 71.78 & -2.73 & 303 \\
\hline Fournier dust & 100 & 36150 & 72.28 & -2.38 & 8 \\
\hline $\begin{array}{l}\text { Fractal hybrid } \\
\text { carpet }\end{array}$ & 100 & 32215 & 75.35 & -2.06 & 1 \\
\hline Sierpinski carpet & 10781 & 55828 & 78.80 & -2.95 & 1 \\
\hline
\end{tabular}

The rank-size distribution of the built clusters shows that the Compact City and the Sierpinski Carpet City have one primate built cluster, which is much larger than the other built clusters (see Figure 3). Moreover, all built clusters except the primate one are almost the same size. In contrast, the rank-size distribution of the Hybrid Fractal Carpet City is clearly hierarchical: although its curve exhibits some plateaus, any shift along the $X$-axis entails a corresponding shift along the $Y$-axis.

Four central clusters feature visually in the Fournier Dust City (Figure 2b). However, according to the analysis conducted using Morpholim, we can see that each "visual" cluster is made up of several built clusters. The rank-size distribution of the built clusters (Figure 3) reveals that eight clusters of about the same size are at the top of the distribution. Those eight clusters form the morphological agglomeration of the Fournier Dust City (Appendix A). For this pattern, variations in the distances between buildings are greater at small scale (i.e. the scale of the medium-sized clusters) than at the scale of the large clusters. Hence this fractal city presents an urban/rural discontinuity at a finer scale (short inter-building distances) than the simple visual analysis of Figure 2b suggests. Moreover, the rank-size distribution exhibits a weak hierarchy: the size of the built clusters varies more than in the case of the Compact City (Figure 2d) and the Sierpsinki carpet (Figure 2a), but less than in the case of the Hybrid Fractal Carpet. 
Figure 3: Rank-size distribution of the built clusters of the theoretical cities.
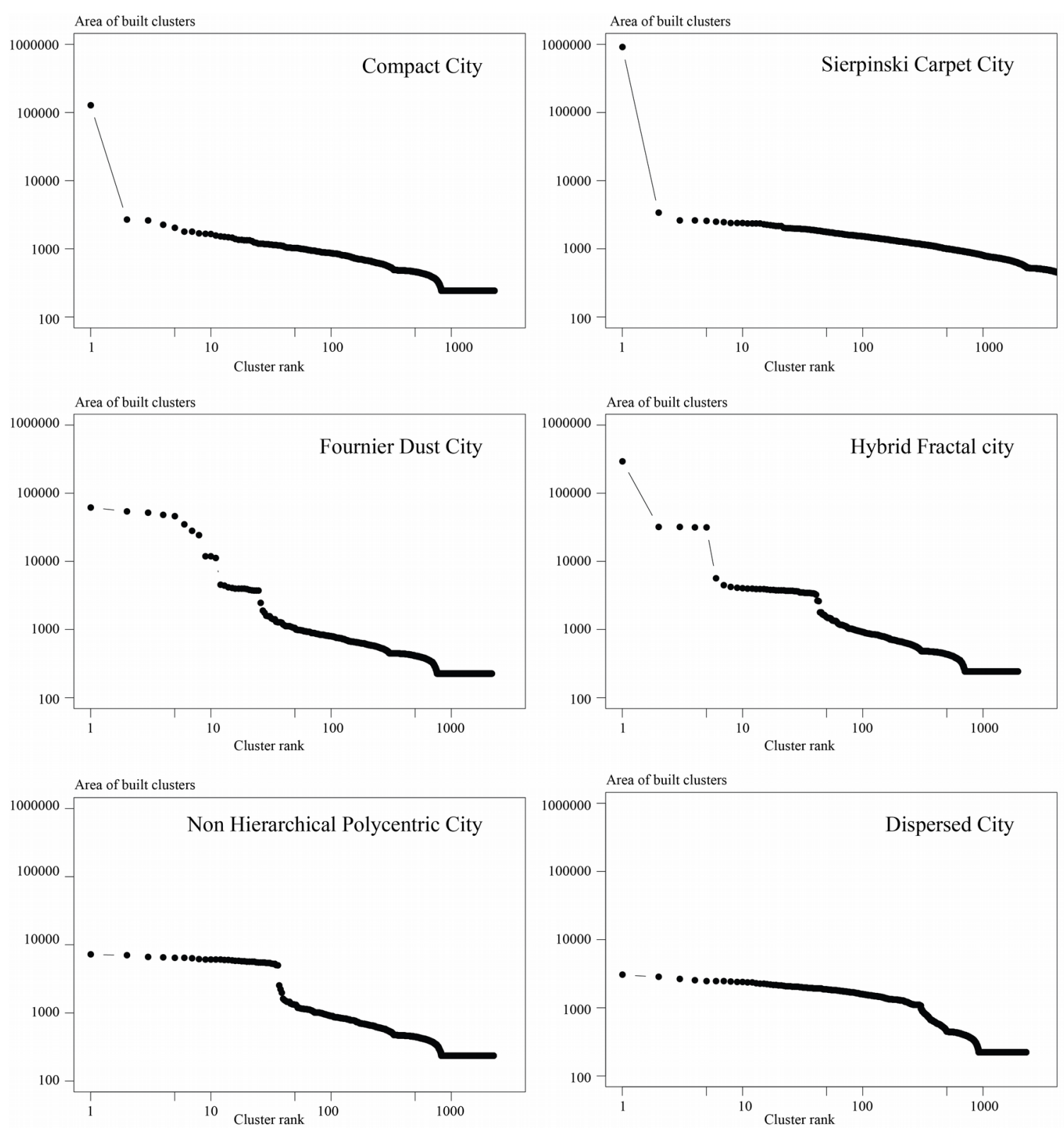

The last two theoretical cities, i.e. the Non Hierarchical Polycentric City (Figure 2e) and the Dispersed City (Figure 2f), have a rank-size distribution characterized by the existence of a large set of built clusters of the same size at the top of the distribution (Figure 3). Their morphological agglomeration is made up of many unconnected built clusters (Appendix A). Their spatial structure is not hierarchical as only two sizes of built clusters are observed. 


\subsection{Characterizing the theoretical urban agglomerations}

Computation of the fractal dimension was only possible for the urban region of the Fournier Dust City and that of the Hybrid Fractal Carpet City (see Column 2 in Table 3, and Appendix E). These are the two urban regions for which the fractality of the urban agglomeration dominates the nonfractality of the surrounding "rural" environment. In practice, two configurations may account for it being impossible to estimate a fractal dimension: (1) when the fractal pattern is diluted within the nonfractal environment (e.g. the Sierpinski carpet), and (2) when the image is made up of fundamentally different patterns that fill space in equal proportions. For example, no fractal dimension can be computed for the morphological agglomeration of the Dispersed City because it is a pattern of 289 regularly spaced discs of equal size. The Dispersed City is somewhat amorphous: depending on the scale of analysis, the fractal dimension varies between 0 (at large scales) and 2 (at fine scales). On the other hand, the built surface and the urban boundary of the Compact City are both characterized by fractal dimensions that are typical of Euclidean shapes: $D_{B}(M A)=1$ and $D_{S}(M A)=1.93$. This latter value is smaller than that theoretically expected (i.e. 2.00) because of the use of square boxes for covering this circular pattern when applying the box-counting analysis.

As expected (Batty \& Longley, 1987; Longley \& Batty, 1989; Chen, 2011), in three patterns out of the six, the dimension of the boundary $D_{B}(M A)$ is greater than 1.0. For the Non Hierarchical Polycentric City pattern, $D_{B}(M A)$ takes values less than 1: it is not a continuous line, but a set of small, unconnected quasi-circles.

Two urban patterns are clearly distinguishable from their environment: the Compact City and the Hybrid Fractal Carpet. They are both characterized by a single largest cluster and a clear difference in morphological properties between the morphological agglomeration and the surrounding built environment. The Compact City is characterized by a very high $D_{S}(M A)$ value and a very low $D_{B}(M A)$ value, whereas the Hybrid Fractal Carpet has a low $D_{S}(M A)$ and a high $D_{B}(M A)$ value. The Compact City is also characterized by a very smooth urban boundary (very low values of $\delta$ and $\mathrm{CO}$ ) and poor access to the urban border. The Hybrid Carpet has much better access to the urban border, which can be 
explained by either $\delta$ or $C O$, but the ratio of buildings belonging to the morphological agglomeration is lower than for the compact city (i.e. fewer buildings potentially have good access to urban amenities).

Table 2: Morphological characteristics of the six theoretical urban agglomerations

\begin{tabular}{|l|c|c|c|c|c|c|c|c|}
\hline City type & $\begin{array}{l}D_{S} \\
(\mathrm{UR})\end{array}$ & $\begin{array}{l}D_{S} \\
(\mathrm{MA})\end{array}$ & $\begin{array}{l}D_{B} \\
(\mathrm{MA})\end{array}$ & $\begin{array}{l}\delta \\
(\mathrm{MA})\end{array}$ & $\begin{array}{l}C O \\
(\mathrm{MA})\end{array}$ & $\begin{array}{l}\% B \\
(\mathrm{MA})\end{array}$ & $\begin{array}{l}\% B- \\
5 m \\
(\mathrm{MA})\end{array}$ & $\begin{array}{l}\% B- \\
150 m \\
(\mathrm{MA})\end{array}$ \\
\hline Compact & - & 1.93 & 1.02 & 0.12 & 0.89 & 88.08 & 1.66 & 29.82 \\
$\begin{array}{l}\text { Non } \\
\text { Hierarchical } \\
\text { polycentric }\end{array}$ & - & - & 0.93 & - & 0.14 & 88.52 & 10.39 & 99.99 \\
$\begin{array}{l}\text { Dispersed } \\
\text { Fournier dust }\end{array}$ & 1.46 & 1.59 & 1.44 & 0.90 & 0.08 & 64.25 & 23.27 & 100.00 \\
$\begin{array}{l}\text { Hybrid fractal } \\
\text { carpet }\end{array}$ & 1.46 & 1.55 & 1.38 & 0.88 & 0.14 & 43.47 & 12.54 & 100.00 \\
Sierpinski carpet & - & 1.41 & 1.47 & 1.04 & 0.03 & 25.22 & 49.27 & 100.00 \\
\hline
\end{tabular}

-: not computable or not fractal; $D$ : box-counting fractal dimension with significance level controlled by an $R^{2}(>0.99)$ and a $p$-value $>>0.01 ; \delta$ : dendricity of the boundary of the MA; CO: compactness of the MA; $\% B(M A)$ : percentage of buildings in the MA; $\% B-5 m(M A)$ and $\% B-150 m(M A)$ : percentage of buildings in the MA within a given distance ( $5 \mathrm{~m}$ or $150 \mathrm{~m}$ ) from the boundary of the MA.

Two patterns are very similar as regards the characteristics of their morphological agglomeration: the Fournier Dust City and the Hybrid Fractal City. It will be remembered, though, that the morphological agglomeration of the former is made up of eight clusters, whereas the $M A$ of the latter is made up of only one cluster. The fact that the morphological centrality of the Fournier Dust City is much weaker will be further discussed (see Section 5).

The more singular spatial patterns are the Sierpinski Carpet and the Compact City. The Sierpinski Carpet City has the smallest number of buildings in the morphological agglomeration, a very long and winding urban boundary, and the best potential access to rural amenities.

The Dispersed City (Figure 2f) offers good potential access to both urban and rural amenities, but this urban pattern does not differ markedly from its rural environment nor 
does it exhibit any morphological centrality. This is also true for the Non Hierarchical Polycentric City (Figure 2e), but less so. The CO index takes a very low value for both the Dispersed City and the Sierpinski Carpet, but the underlying morphological realities are different: multiple dispersed clusters (high built fragmentation) for the Dispersed City, a single cluster for the Sierpinski Carpet City.

Some general features can be pointed out here:

(1) The more the boundary of the morphological agglomeration is dendritic and winding (large $\delta$ values and low $C O$ values), the higher the percentage of buildings close to the urban/rural fringe. This is quite interesting in terms of land-use planning and residential choices as inhabitants look - among other things - for spacious accommodation close to the countryside with a pleasant view (Cavailhès et al., 2009).

(2) Characterizing the shape of the urban boundary alone may be insufficient as it may interact with the fragmentation of the built pattern and its more or less hierarchical organization.

(3) Fractal cities and non-fractal cities do not systematically share the same characteristics. Each theoretical city has its own characteristics.

\section{BELGIAN URBAN AGGLOMERATIONS}

\subsection{Studied areas}

Belgium is a small European country: its size is comparable to that of the Extended Metropolitan Area of New York $^{1}$ but with far fewer inhabitants: the country has 11 million inhabitants and is characterized by a tight city network dominated by the centrally located primate city of Brussels. In such a small country, urban hinterlands often overlap. Three administrative regions (Flanders, Wallonia, and Brussels Capital Region, see Appendix B) partition the country with different land use planning policies (Albrechts, 2001). In the northern part, population density is significantly greater, land is scarcer, plots are smaller, and housing is more recent, while in the southern part, the city network is less tight, plots are larger, land is less expensive, and housing is larger and

\footnotetext{
${ }^{1}$ Belgium = 30528 sq km; extended metropolitan area of New York = 30671 sq km
} 
older (Vanneste et al., 2007). The Brussels Capital Region (BCR) is located in the center of the country; it is a highly and fully urbanized region corresponding to the center of the Brussels’ urban agglomeration (which sprawls into Flanders and Wallonia).

Belgian cities are characterized by a strong center-periphery structure with better-off households located in the peripheries (Verhetsel, Thomas and Beelen, 2010). As in many European countries, urban sprawl has affected Belgian cities for more than 40 years leading to fragmented landscapes that have developed in space and time (Antrop, 2004). Urban planning has often been very slack especially in Wallonia, and "laissez-faire" has prevailed over the years (Albrechts, 2001; Antrop, 2004).

The 18 largest cities are studied here (Appendix B). We assume that each urban region corresponds to the "extended urban agglomerations" defined by Van Hecke, Halleux, Decroly, and Mérenne-Schoumacker (2009). They all have a historical city-center around which the city has developed and sprawled. As expected, the size of the Belgian urban regions varies much more than in the six theoretical cases.

\subsection{Delineating the Belgian morphological agglomerations}

Morpholim found a solution for each city: this means that it is possible to identify a morphological agglomeration (MA) within each Belgian urban region (UR). This argument is in line with Van Criekingen, Cornut, and Luyten (2007), who claim that Belgian cities are still separate entities, and goes against the idea of an urban-rural continuum, or, the idea that Belgium is one large conurbation (Vandermotten, Roelandts, Halbert and Cornut, 2008).

Observed curvature values are closer to zero for the 18 Belgian cities than for the six theoretical cities (see Appendix C). This means that dilation curves are on average closer to a line and the urban/rural difference smaller for Belgian cities than for our theoretical cities (Figure 4 and Appendix D). In general, a polynomial of degree 5 or 6 was the most appropriate. In four cases out of 18 (i.e. Brussels, Genk, Hasselt, and Saint-Niklaas), the value of maximum curvature is low for a polynomial of low degree; hence the distance 
threshold was identified on a higher order polynomial characterized by a larger value of maximum curvature.

Figure 4. The dilation curves of eight Belgian cities, which are exemplary in terms of their curvature
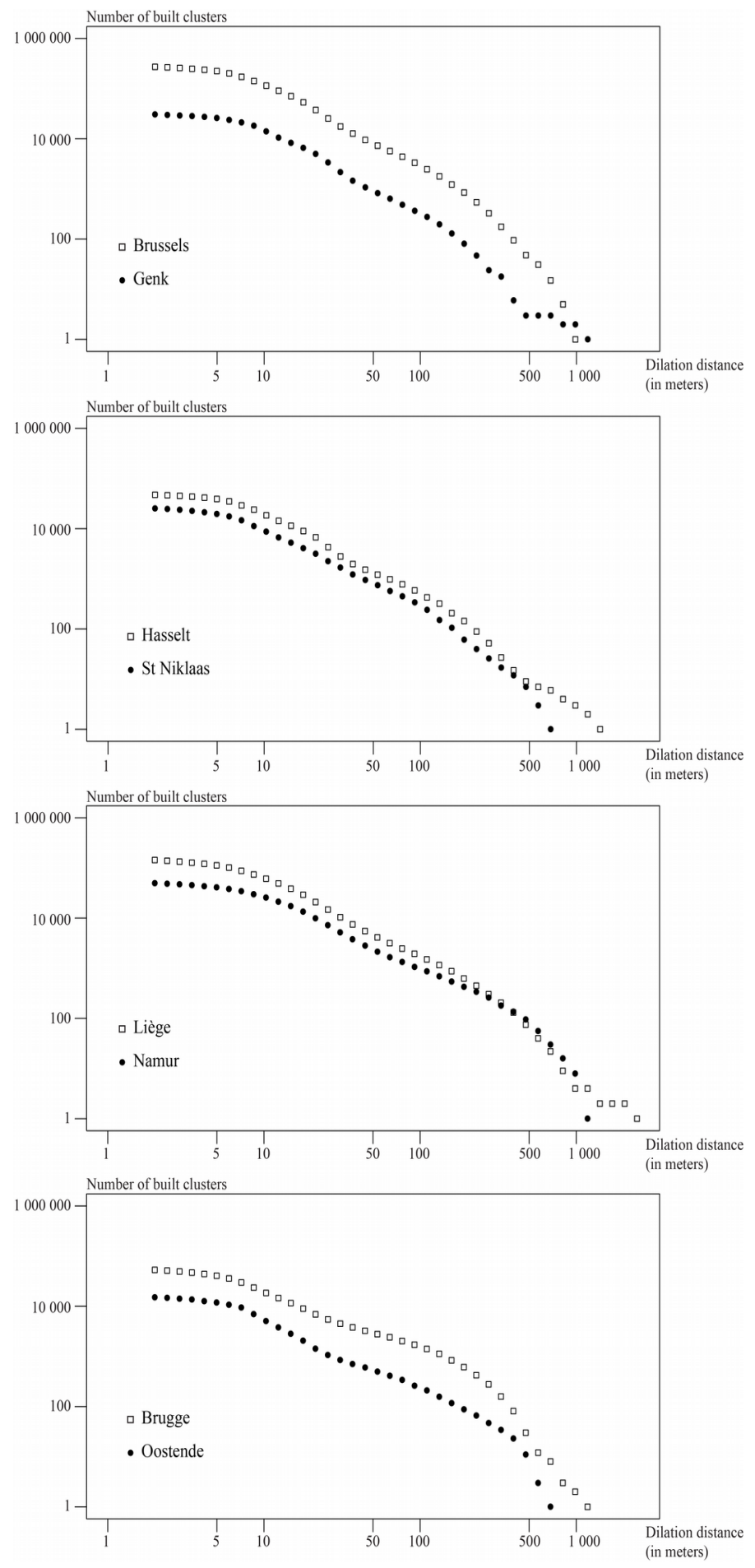
Distance thresholds identified when delineating the Belgian morphological agglomerations vary substantially: from $77 \mathrm{~m}$ for Saint-Niklaas to $330 \mathrm{~m}$ for Namur. This illustrates the diversity of city shapes in Belgium.

Figure 5: Rank-size distribution of the built clusters of six Belgian cities.
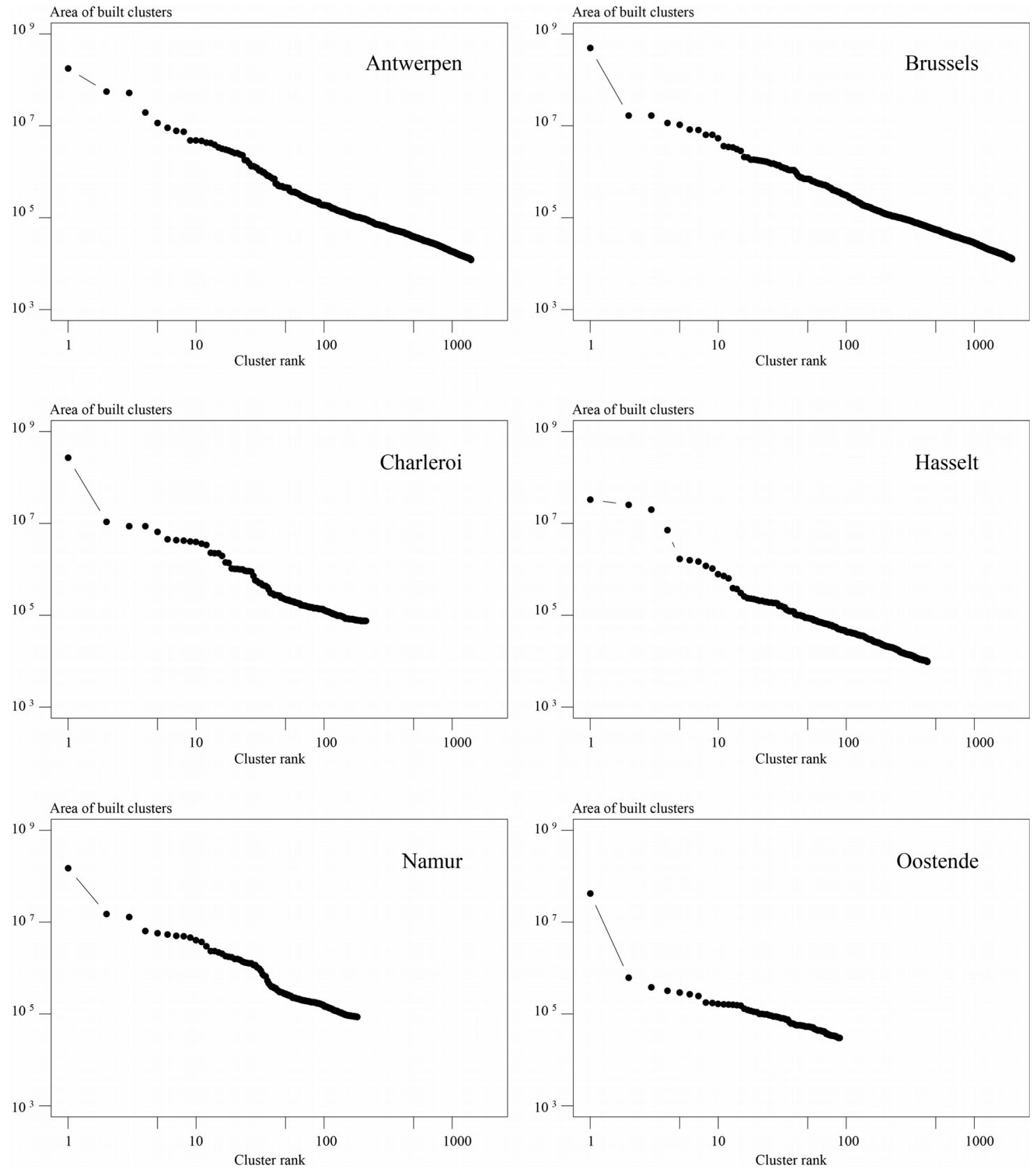

Figure 5 displays the rank-size distribution of six cities illustrating the variety of all Belgian rank-size distributions. Some cities (e.g. Brussels, Oostende) exhibit a primate 
distribution, others (e.g. Antwerpen) not. The rank-size curves of Hasselt and the Fournier Dust City are very similar: these two cities have several large clusters of almost the same size at the top of the distribution. In each case, even for Hasselt, it is easy to identify the morphological agglomeration. Moreover, all rank-size distributions are clearly hierarchical as in the case of the Hybrid Carpet City or even the Fournier Dust City.

A monocentric morphological agglomeration has been identified in each Belgian urban region. This morphological agglomeration is made up of either one cluster or, in the case of Hasselt, three clusters close to each other. Hence Belgian cities are very different from the Dispersed City and the Non Hierarchical Polycentric City.

\subsection{Characterizing the Belgian agglomerations}

Fractal dimensions computed for the 18 Belgian cities are all significant (Table 3 and Appendix F). This was not the case for the Dispersed City and the Non Hierarchical Polycentric City, and confirms that these patterns clearly differ from Belgian cities. Consequently, Belgian cities will not be further compared here to them.

$R^{2}$ values observed for Belgian cities (0.9) are lower than those for theoretical cities (0.99). In order to improve the goodness-of-fit, we tried to estimate the fractal dimension over a smaller range of box sizes defined specifically for each map, as suggested by Feng and Chen (2010) and Chen (2011). This did not lead to any increase in $R^{2}$ probably because of the very high quality of the data used: source images are very detailed and exhibit a high number of internal lacunas of various sizes, which leads to a high variability in the number of counted boxes. Lower resolution maps, used for instance by Benguigui et al. (2000), Shen (2002), and Feng and Chen (2010), lead to fractal dimensions that are not comparable.

Computed fractal dimensions $D_{S}(M A)$ vary between 1.5 and 1.7 , characterizing built patterns that are partially connected and partially unconnected across scales and obeying a hierarchical organization, such as the Hybrid Fractal Carpet or the Fournier Dust City. $D_{S}(U R)$ is usually lower than $D_{S}(M A)$, which confirms the morphological difference between the morphological agglomeration and its surrounding built environment. For 
three cities with dilation curves characterized by a low value of maximum curvature for a polynomial of low degree (Brussels, Genk, Hasselt), almost no difference between $D_{s}(U R)$ and $D s(M A)$ is observed, suggesting that the morphological agglomeration of these cities is not much different from their surrounding environment. This is, however, not the case of the fourth city with a dilation curve characterized by a low value of maximum curvature for a polynomial of low degree (Saint-Niklaas). Conversely, Oostende exhibits almost no difference between $D_{S}(U R)$ and $D_{S}(M A)$ although its dilation curve exhibits a strong curvature. This could be explained by the very high proportion of buildings of the UR belonging to the MA (\%B(MA)). However, some cities also with high $\% B(M A)$ values nevertheless exhibit a clear difference between $D_{S}(U R)$ and $D_{S}(M A)$ (e.g. Liège and Kortrijk). All these results illustrate the diversity of the Belgian urban morphologies and the uniqueness of each city.

Table 3: Morphological characteristics of 18 Belgian cities

\begin{tabular}{|c|c|c|c|c|c|c|c|c|c|}
\hline Town & $\begin{array}{l}1000 \\
\text { inhabitant } \\
\text { s in } U A *\end{array}$ & $\begin{array}{l}D_{s} \\
\text { (UR) }\end{array}$ & $\begin{array}{l}D_{S} \\
\text { (MA) }\end{array}$ & $\begin{array}{l}D_{B} \\
\text { (MA) }\end{array}$ & $\begin{array}{l}\delta \\
\text { (MA) }\end{array}$ & $\begin{array}{l}\mathrm{CO} \\
\text { (MA) }\end{array}$ & $\begin{array}{l}\text { \%B } \\
\text { (MA) }\end{array}$ & $\begin{array}{l}\% B- \\
5 m \\
\text { (MA) }\end{array}$ & $\begin{array}{l}\% B- \\
150 m \\
\text { (MA) }\end{array}$ \\
\hline $\begin{array}{l}\text { Antwerpe } \\
n\end{array}$ & 941 & 1.62 & 1.68 & 1.61 & 0.95 & 0.04 & 55.37 & 8.03 & 52.54 \\
\hline Brugge & 166 & 1.51 & 1.62 & 1.47 & 0.90 & 0.09 & 59.82 & 7.72 & 54.77 \\
\hline Brussels & 1789 & 1.60 & 1.63 & 1.61 & 0.99 & 0.02 & 82.01 & 11.07 & 59.53 \\
\hline Charleroi & 404 & 1.55 & 1.59 & 1.62 & 1.01 & 0.06 & 89.38 & 4.34 & 34.96 \\
\hline Genk & 88 & 1.54 & 1.54 & 1.56 & 1.01 & 0.06 & 72.60 & 17.24 & 77.93 \\
\hline Gent & 416 & 1.60 & 1.66 & 1.60 & 0.96 & 0.06 & 51.30 & 7.81 & 55.57 \\
\hline Hasselt & 127 & 1.52 & 1.53 & 1.34 & 0.86 & 0.04 & 79.00 & 23.49 & 83.53 \\
\hline Kortrijk & 143 & 1.57 & 1.65 & 1.53 & 0.92 & 0.07 & 80.58 & 9.82 & 62.07 \\
\hline Leuven & 170 & 1.51 & 1.55 & 1.51 & 0.98 & 0.05 & 70.47 & 15.34 & 71.41 \\
\hline Liège & 634 & 1.54 & 1.61 & 1.66 & 1.03 & 0.04 & 81.59 & 9.19 & 58.08 \\
\hline Mechelen & 134 & 1.58 & 1.61 & 1.61 & 1.00 & 0.05 & 69.95 & 15.64 & 73.43 \\
\hline Mons & 232 & 1.52 & 1.57 & 1.59 & 1.01 & 0.05 & 82.53 & 9.22 & 61.81 \\
\hline Namur & 153 & 1.45 & 1.50 & 1.54 & 1.03 & 0.08 & 74.77 & 6.90 & 37.94 \\
\hline Oostende & 93 & 1.55 & 1.56 & 1.44 & 0.92 & 0.11 & 98.23 & 7.22 & 48.94 \\
\hline St Niklaas & 87 & 1.53 & 1.62 & 1.57 & 0.97 & 0.07 & 57.24 & 18.38 & 87.31 \\
\hline Tournai & 88 & 1.46 & 1.54 & 1.48 & 0.96 & 0.09 & 44.32 & 10.87 & 62.82 \\
\hline Turnhout & 76 & 1.49 & 1.56 & 1.52 & 0.97 & 0.11 & 73.85 & 5.49 & 36.52 \\
\hline Verviers & 97 & 1.44 & 1.54 & 1.56 & 1.01 & 0.07 & 81.12 & 15.26 & 71.95 \\
\hline
\end{tabular}

$D$ : box-counting fractal dimension with $R^{2}$ greater than 0.9 and a $p$-value $<<0.01 ; \delta$ : dendricity of the boundary of the MA; $C O$ : compactness of the MA; \%B(MA): percentage of buildings in the MA; $\% B$ $5 \mathrm{~m}(\mathrm{MA})$ and $\% \mathrm{~B}-150 \mathrm{~m}(\mathrm{MA})$ : percentage of buildings in the MA within a given distance (respectively $5 \mathrm{~m}$ and $150 \mathrm{~m}$ ) of the boundary of the MA. 
Fractal dimensions $D_{B}(M A)$ are all higher than those measured for the three fractal theoretical cities whereas $\delta$-values (min: 0.90; max: 1.03) fall within the range of values obtained for these three theoretical fractal cities. This confirms the highly irregular and dendritic shape of the urban/rural boundaries of the Belgian cities. The lowest values are obtained for three Flemish cities (Brugge, Oostende, and Kortrijk) all located in the Western part of Flanders, which have $\delta$-values close to those of the Hybrid Carpet City and the Fournier Dust City. By contrast, Liège and Namur have the highest $\delta$-values; they are both located in the Meuse valley and at confluences. $\delta$-values slightly greater than 1 mean that $D_{B}(M A)$ is slightly higher than $D_{S}(M A)$, which is the case of Charleroi, Genk, Hasselt, Liège, Verviers, and Namur, as well as the Sierpinski Carpet City.

$\mathrm{CO}$ values are not very discriminating in terms of observed built-up footprints. All Belgian agglomerations are a long way from being as compact as the Compact City. However, even though the range of $\mathrm{CO}$ values of Belgian cities is narrow, the observed differences do have a geometrical meaning (Bogaert, Rousseau, Van Hecke \& Impens, 2000) and allow different types of city shapes to be distinguished. Some Belgian cities are similar to the Hybrid Carpet City, which has a $C O$ value of 0.14; other Belgian cities are close to the Sierpinski Carpet City, which has a $C O$ value of 0.03 . The lowest $C O$ value is observed for Brussels, which is by far the largest Belgian city in terms of both population and area.

The proportion of buildings of the UR belonging to the MA (\%B(MA)) varies greatly across the cities: from $40 \%$ in Hasselt to $98 \%$ in Oostende. The proportions of UR buildings belonging to the MA and located within 5 meters of the urban boundary (\%B$5 m(M A))$ are close to those computed for the Hybrid Fractal Carpet City. However, the boundary of the latter is less dendritic and not as winding. Contrariwise, Belgian cities are characterized by a very indented border. This is different for $\% B-150 m(M A)$ : all Belgian cities have a lower value than any of our theoretical cities with the exception of the Compact City. Interestingly, on average, Flemish cities have a lower proportion of buildings within the MA (\%B(MA)) and a higher proportion of buildings close to the 
urban boundary than Walloon cities. This is to be related to the different urban histories and geographies of northern and southern Belgium, and especially the higher population density as well as the stricter urban planning policy in Flanders (North).

At this stage, we can say that no Belgian city really looks like any of the theoretical cities when considered across the entire set of indexes. Each Belgian city may look like a theoretical city in one respect but is very different in other respects. Belgian cities share several common characteristics: they all have a clear monocentric morphological agglomeration; their rank-size distributions of built-up clusters are hierarchical as in the case of the Hybrid Carpet City or the Fournier Dust City; their built pattern is fractal ( $D_{S}(U R), D_{S}(M A)$, and $D_{B}(M A)$ could be calculated for all Belgian cities); their boundary is highly dendritic $\left(D_{B}(M A)\right.$ values of Belgian cities are always greater than those measured for the three fractal theoretical cities and for the Compact City as well); few buildings are located close to the urban boundary (\%B-150m(MA) values are close to the value computed for the Compact City).

These common characteristics aside, the morphology of Belgian cities differs substantially: distance thresholds computed using Morpholim are very different from each other, rank-size distributions of built clusters do not always exhibit a primate cluster, the observed $\% B(M A)$ values are diverse, being either close to the value of the Compact City or close to the values of the theoretical fractal cities, variations of $\delta$ and $C O$ are less apparent but even so differences can be interpreted ( $\delta$ and $C O$ values of Belgian cities are closer to the values of either the Hybrid Carpet or the Sierpinski Carpet City).

\subsection{Multivariate exploratory analyses}

\subsubsection{Do indexes co-vary?}

The eight selected morphological indexes co-vary little within the set of 18 Belgian agglomerations (Table 4). Notice that given the small number of observations and the nature of some indexes, this analysis is purely exploratory and the level of significance used here is broad (10\%). 
Table 4: Pearson correlation coefficients between the morphological indexes computed for the 18 Belgian cities (ns: not significant at a 0.10 significance level).

\begin{tabular}{|l|c|c|c|c|c|c|c|c|}
\hline & & $D_{S}$ & $D_{S}$ & $D_{B}$ & $\delta$ & $C O$ & $\% B$ & $\% B-5 m$ \\
\cline { 3 - 9 } & & UR & MA & MA & MA & MA & UR/MA & MA \\
\hline$D_{S}$ & MA & $\mathbf{0 . 8 2}$ & & & & & & \\
$D_{B}$ & MA & 0.48 & 0.42 & & & & & \\
$\delta$ & MA & ns & $-0,44$ & 0.62 & & & & \\
$\% B$ & MA & $-0,49$ & ns & $-0,76$ & ns & & & \\
$\% B-5 m$ & UR/MA & ns & ns & ns & ns & ns & & \\
$\% B-150 m$ & MA & ns & ns & ns & ns & ns & ns & \\
\hline Area & MA & ns & ns & ns & ns & ns & ns & $\mathbf{0 . 9 3}$ \\
Built-up density & MA & ns & ns & 0.60 & ns & $-0,58$ & ns & ns \\
& MA & 0.58 & 0.74 & ns & -0.61 & ns & -0.49 & ns \\
\hline
\end{tabular}

Built density in the MA is strongly correlated to $D_{S}(M A)$ : as expected, high densities are also synonymous with a high fractal dimension of the built-up footprints $D_{S}(M A)$. Similarly, the higher the density, the smaller $\% B$. In contrast, built density in the MA is not correlated to $D_{B}(M A)$ and $C O$. Interestingly, the size (area) of the morphological agglomeration exhibits opposing correlations: no correlation between area and $D_{S}(M A)$ whereas $D_{B}(M A)$ values vary significantly with the area of the MA: the larger the MA, the more the urban boundary exhibits nested convolutions. This illustrates that the relationship between the shape of MA boundaries (i.e. their outline) and the built morphology within the MA is not simple and cannot be easily and uniquely characterized. Consequently, both aspects have to be considered when analyzing built patterns. The dendricity index $\delta$ provides a way to take them into account jointly. Interestingly, $\delta$ is not correlated to the $C O$ index because of the absence of correlation between $D_{S}(M A)$ and $C O$, whereas $D_{B}(M A)$ is correlated to the $C O$ index.

Results for the theoretical cities suggest that a highly dendritic boundary leads to a high $\% B-5 m(M A)$ value; this is particularly the case of the Sierpinski Carpet and the Fournier Dust City. This is clearly not the case for the Belgian cities. Neither the fractal dimension nor the dendricity of the MA boundary is associated with access to the urban boundary; this means that fractal lengthening of the urban boundary in Belgium does not imply 
more buildings close to that line. In particular, Walloon cities tend to have a high dendricity and proportionally few buildings located on the urban boundary. Conversely, the two indexes characterizing access to the urban boundary (\%B-5m(MA) and $\% B$ $150 \mathrm{~m}(M A))$ are highly correlated ( $r=0.93$ ), meaning that whatever the Belgian city, these two variables are proportional. This was not the case for the theoretical cities (Section 3).

\subsubsection{Do the Belgian and theoretical cities look alike?}

To compare the profiles of the studied cities on the basis of the selected morphological indexes, a hierarchical classification with a Ward criterion on the standardized data was simply performed (JUMP software); the Ward criterion minimizes intra-group variation and maximizes inter-group variation. Given the observed correlation coefficients and the missing values for the fractal dimensions of our theoretical cities, two indexes were omitted from the analysis $\left(D_{S}(U R)\right.$ and $\left.\% B-150 m\right)$. Figure 6 displays the clustering results; the cities are best clustered into six groups.

Figure 6. Clustering 18 Belgian cities together with four theoretical cities (distance criterion standardized): dendrogram based on distance.

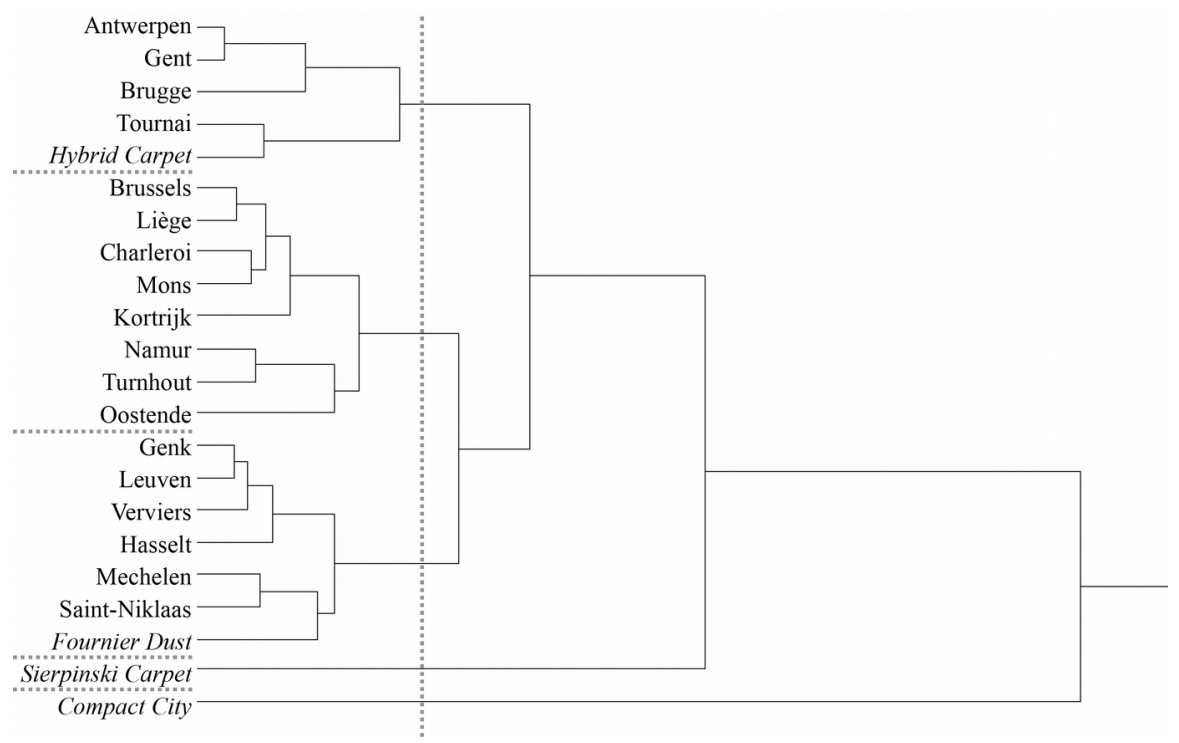

As expected, the Compact City corresponds to a highly specific spatial morphology, which is very different from any other city studied here: it remains a singleton up to the end of the clustering procedure. No Belgian city is compact, which is unsurprising, but 
raises concerns when considering certain broad "sustainable" European planning objectives.

The Sierpinski Carpet City also behaves as a singleton in the dendrogram, but it merges with the other cities before the Compact City. Belgian cities are a little less different from the Sierpinski Carpet than from the Compact City.

Figure 7. MA and UR of four typical Belgian cities
(a) Antwerpen
(b) Brussels
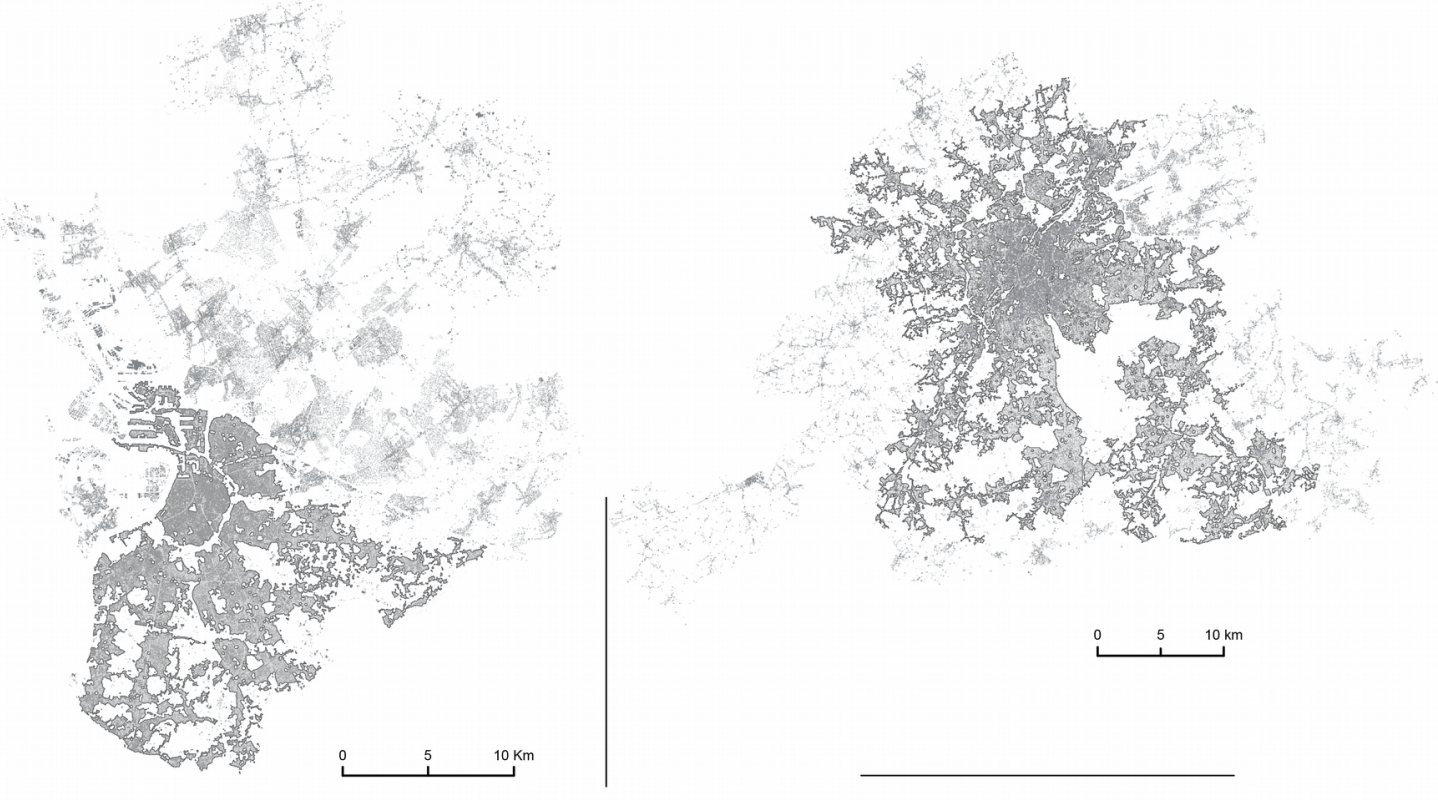

(c) Hasselt

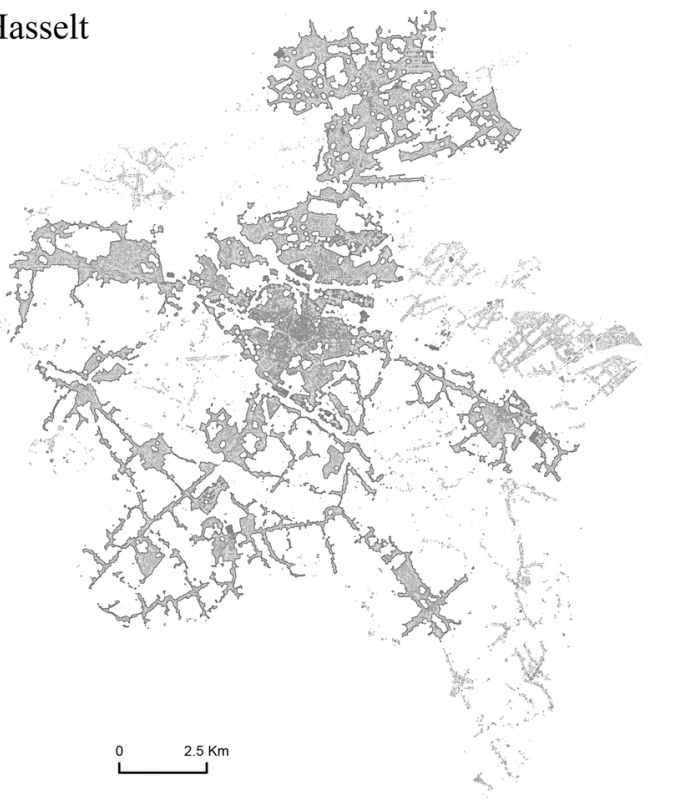

(d) Charleroi

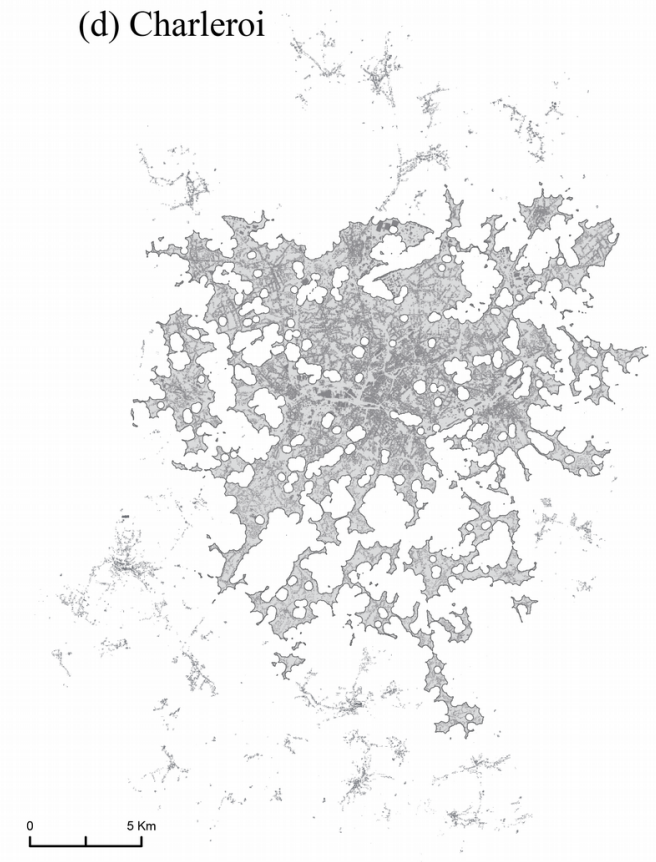


Antwerpen (Figure 7a), Gent, Brugge, and Tournai cluster with the Hybrid Carpet City. All these cities are hierarchically organized and fractal. There is one central cluster in these cities, and the urban boundary is not as clear-cut as in the other Belgian cities.

A last group of cities splits into two subgroups: one does not include any theoretical city (see Figure 7b Brussels, and Figure 7d Charleroi) while the other groups Belgian cities as well as the Fournier Dust City (see Figure 7c Hasselt).

We previously noticed that Flemish cities have, on average, high observed built-up densities and low dendricity, while Walloon cities like Liège, Charleroi, and Namur have low built-up densities and high dendricities. However, the composition of the clusters reveals that it is hard to demonstrate an effect of the Region (no clear-cut Flemish/Walloon difference), or of the size of the city, or of any specific feature for the clustering of Belgian cities, but that some cities resemble theoretical (fractal) structures.

\section{CONCLUSION}

This research contributes to the operationalization of some mathematical and computerbased tools devised for analyzing and modeling cities. With very simple Land Registry data, a fractal method was used for extracting the morphological agglomeration within theoretical urban regions and real Belgian regions. A set of spatial indexes was used to compare the morphological agglomerations considering the shape both of their boundaries and their internal built patterns.

\subsection{Measuring the shape of morphological agglomerations}

As expected, the morphological boundary between each Belgian urban agglomeration and its hinterland is fuzzier than that of the theoretical urban patterns, but it was nevertheless possible to identify a "morphological agglomeration” in each case study: Belgium has a tight-knit city network but the built-up pattern of Belgium is not yet a morphological continuum from a fractal point of view. The straightness of some dilation curves shows, however, that the built pattern of some Belgian urban regions tends to resemble a fractal continuum (Brussels, Genk, Hasselt, St Niklaas). In these cases, the 
distances separating built elements tend to comply with a strict hierarchical law. Nevertheless, the rank-size distributions of the built clusters of those four cities are no more hierarchical than the rank-size distributions of the built clusters of other cities. In particular, even when the dilation curve is close to a straight line, a primate cluster may be found at the top of the hierarchy of the built clusters. This suggests that the morphological delineation of urban agglomerations is significantly more meaningful when taking into account both the variation across scales of distances separating buildings and the variation of the size of built clusters. With our methodology, both aspects are considered jointly because built clusters are identified by the multiscale analysis of interbuilding distances.

The shape of the morphological agglomerations so defined has further been characterized using fractal and nonfractal indexes. The results show that the larger the morphological agglomeration, the more the urban boundary exhibits nested convolutions. This should be further analyzed with respect to Chen's (2011) suggestion that an increase in urban perimeter does not imply an increase in the complexity of the boundary.

The results also confirm that the morphology of the urban boundary is not that of the built-up fabric. Some authors have already shown that the fractal dimension of the built surface area increases and the fractal dimension of the urban boundary decreases with city growth (Benguigui et al., 2000). Consequently, dendricity should decrease over time. We could not confirm this for Belgium, simply for lack of time series data: Land Registry data were made available in 2009 for the first time in a uniform digitized form. However, we have shown that dendricity is not correlated with the surface of the MA, whereas it is negatively correlated with the MA built-up density. It might be interesting to further analyze this relationship between dendricity and MA built-up density, knowing that urbanization is (at least partly) a space-filling process.

\subsection{Comparing Belgian urban agglomerations}

Clear intercity variations were observed regarding the range of differences between $D_{S}(M A)$ and $D_{S}(U R)$, but no relationship was established with either the curvature value 
of the dilation curve, or the proportion of buildings in the UR that are part of the MA, or even the straightness of the dilation curve.

The relationship between the length of the city boundaries and the proximity of the residents to both rural and urban amenities has been explored. The analysis of theoretical cities showed that an agglomeration with a long perimeter compared to its area could have a large proportion of buildings located close to its urban boundary. However, unlike with our theoretical cities, in the case of Belgian cities no relationship could be established between the number of buildings located in the vicinity of the boundary and the fractal dimension or the compactness of the urban boundary. We can easily state that, in Belgium, buildings located close to the urban/rural boundary are characterized by a fractal dimension that is lower than that measured for the urban boundary itself. The relatively high fractality of the boundary might allow more buildings to be located very close to the urban boundary without hampering access to rural amenities by dwellings currently located on the urban boundary.

Flemish cities tend to have (but not systematically) a lower dendricity and a higher proportion of buildings close to the urban boundary than Walloon cities. This suggests that only a few supplementary buildings can be constructed on the urban boundary of Flemish cities without expanding the urban boundary itself: access to the urban boundary for people living within the MA is nearly maximized and cannot easily be increased. Conversely, potential access to the urban boundary of Walloon cities seems to be underused: the number of buildings close to the urban boundary might be increased without hampering access to the urban boundary from buildings currently located on it. In addition, Flemish towns have in general a higher built-up density than Walloon towns; they are therefore more compact on this index. However, they are characterized by a smaller proportion of buildings within the MA than Walloon towns. Hence it may be that more people live in peri-urban zones (as defined from a purely morphological point of view). These conclusions are consistent with other analyses of the residential situation in Belgium (Vanneste et al., 2007). 


\subsection{Insight into planning possibilities}

In this paper, we have put forward some morphological characteristics, which are usually not considered from a multiscale point of view when comparing the value for planning of different urban shapes: the range of variation of interbuilding distances within and outside the morphological agglomeration, the primacy of the rank-size distribution of built clusters, the possibility of constructing new buildings very close to the urban boundary without increasing its length. However, at this stage of the research we cannot determine whether the existence of a primate cluster is favorable or not, or if a city shape similar to a Hybrid Fractal Carpet is better than another city shape.

Considering the morphological indexes measured here, Belgian cities look more like fractal cities (especially the Hybrid Carpet City) than like the Compact City and even the Dispersed City or the Non Hierarchical Polycentric City. Nevertheless, compactness is valuable for planning purposes because all buildings are in the largest built cluster, which reduces built fragmentation. But compactness also has its disadvantages: poor access to rural amenities because of the smoothness of the urban boundary $\left(D_{B}(M A)=1\right)$ and a lack of intraurban built diversity ( $D_{s}(M A)$ close to 2$)$.

Falling in-between dilution (or dispersion) and compactness, the Hybrid Carpet City represents a mixed solution with one main cluster (with $43 \%$ of the buildings of the urban region) and a few hierarchically-organized secondary clusters. Four Belgian cities come very close to this spatial organization.

Finally, our methodology and results raise at least two questions about the value of different city shapes with respect to the criteria of sustainable urban development: (1) Would it be worth creating urban development plans combining the compact city model and the fractal city model (instead of considering them as competing models)? If so, one possible planning goal could be to increase the built density according to the fractal logic. (2) Would it be worth it for planners to reduce (or increase) the primacy of the intraurban rank-size distribution of built clusters? Addressing these questions would allow us to better understand the functional implications of both fractal and nonfractal shapes of cities. 


\section{Acknowledgments}

The authors would like to thank Gilles Vuidel for his technical and methodological support, especially in developing Morpholim and Fractalyse, as well as Armelle Couillet for her support in drawing some of the figures. Most computations were performed on the supercomputer facilities of the "Mésocentre de Calcul de Franche Comté”. 


\section{Appendix A}

Outline of the largest built cluster(s) identified for the six theoretical cities
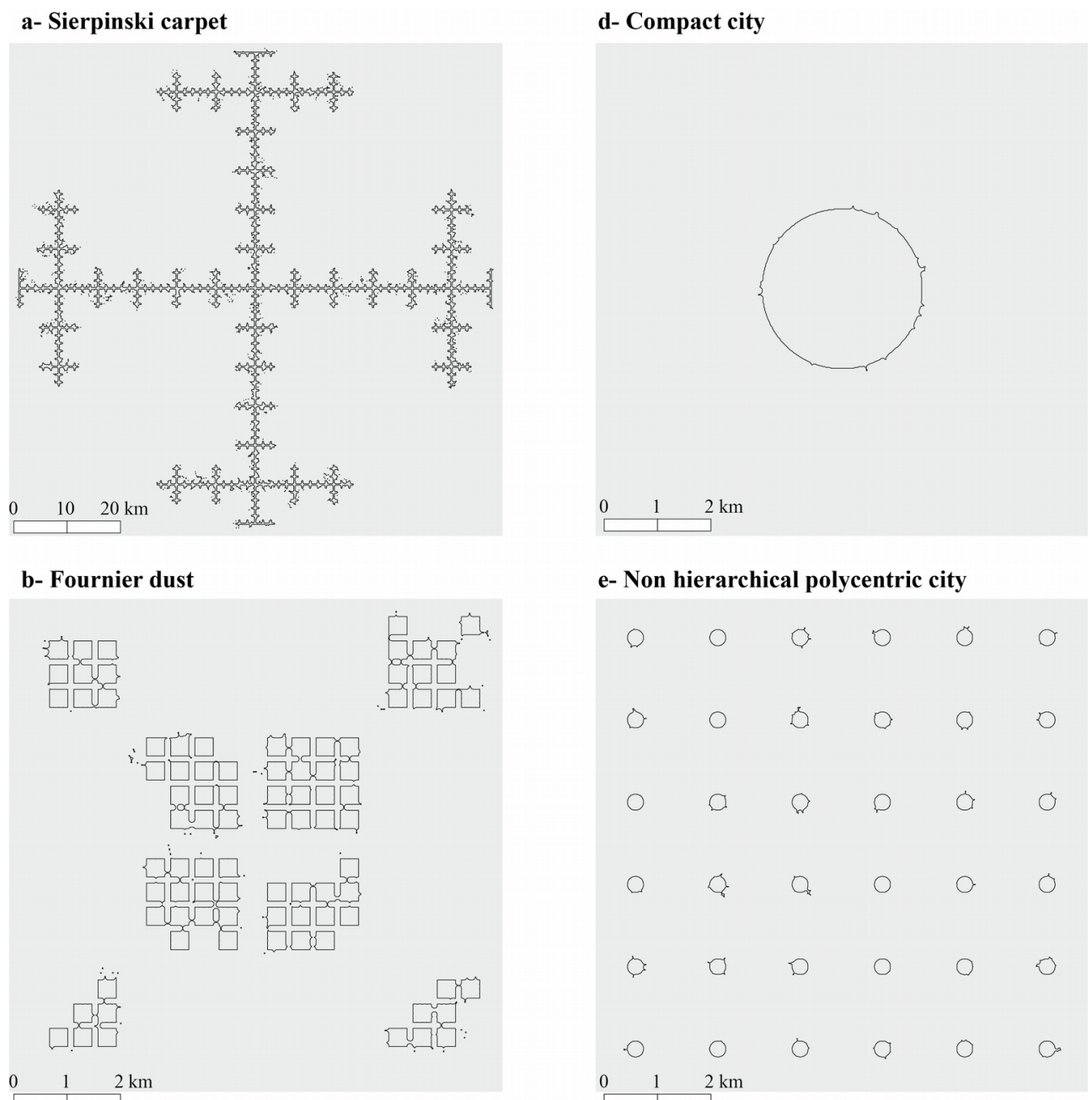

e- Non hierarchical polycentric city
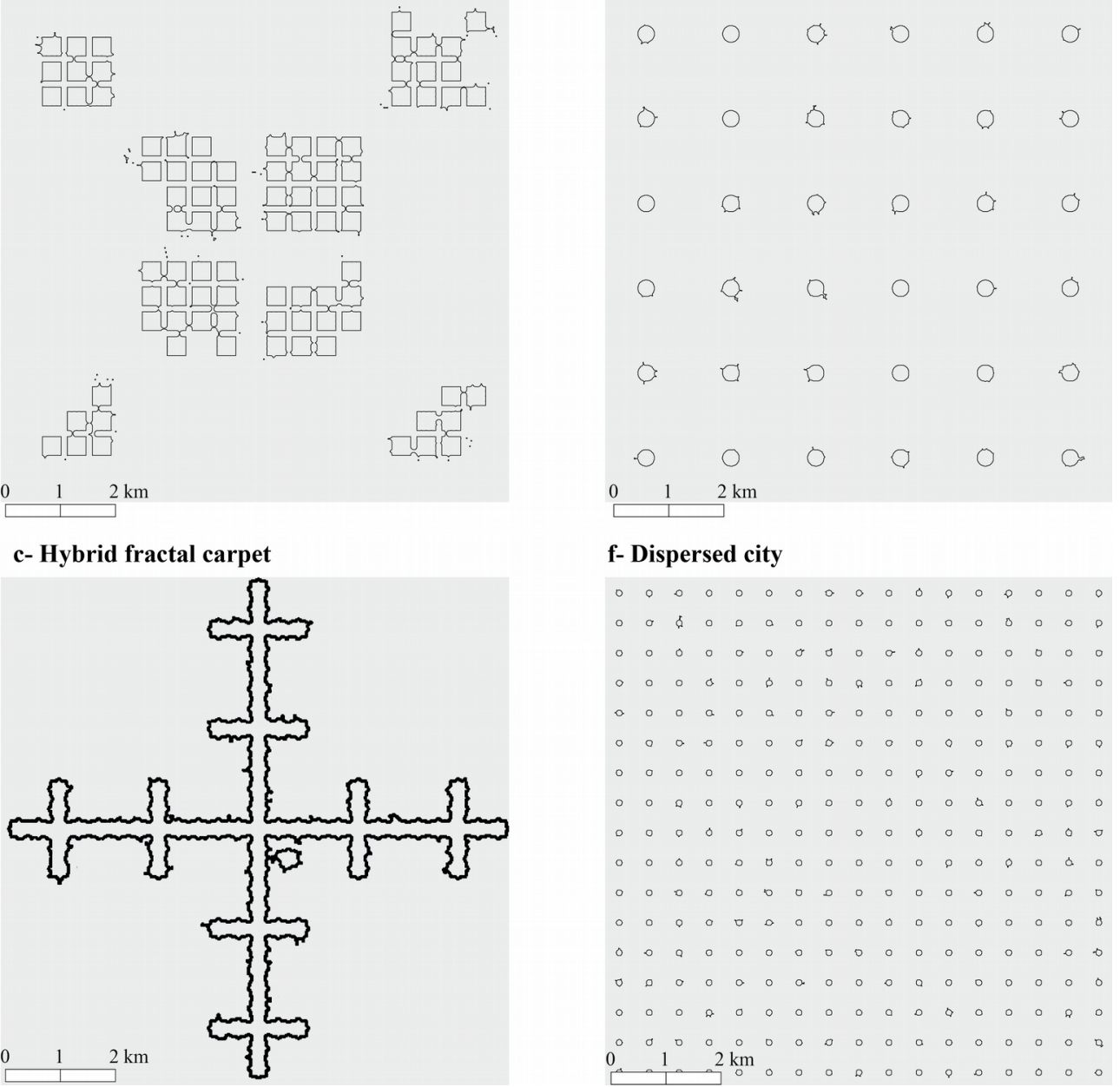


\section{Appendix B}

Location of the centers of the 18 largest Belgian cities and regional borders

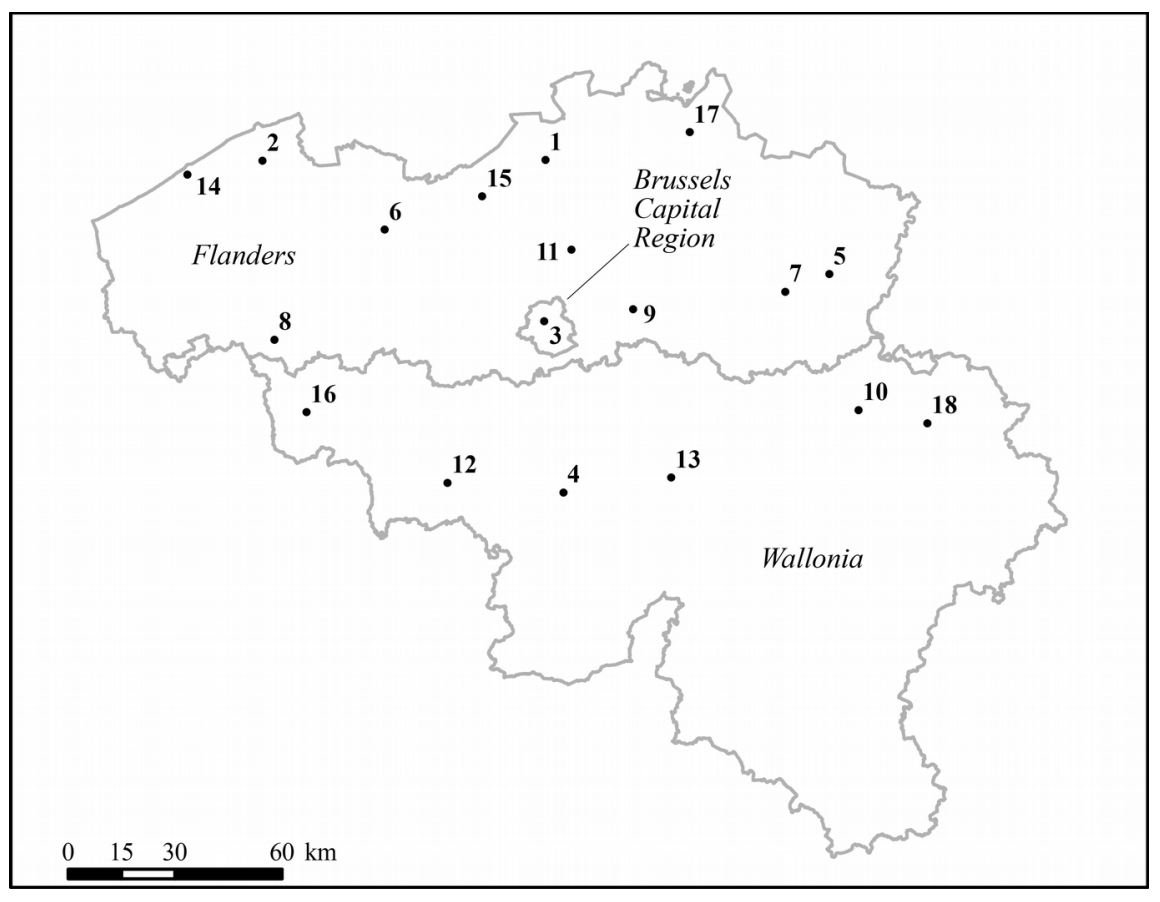

where 1: Antwerpen, 2: Brugge, 3: Brussels, 4: Charleroi, 5: Genk, 6: Gent, 7: Hasselt, 8: Kortrijk, 9: Leuven, 10: Liège, 11: Mechelen, 12: Mons, 13: Namur, 14: Oostende, 15: Saint Niklaas, 16: Tournai, 17: Turnhout, 18: Verviers. 


\section{Appendix C}

Extracting the urban boundaries of the 18 largest Belgian urban agglomerations: structural indexes

\begin{tabular}{|l|r|r|r|r|r|}
\hline City & $\begin{array}{l}\text { Political } \\
\text { region }\end{array}$ & $\begin{array}{l}\text { No. of } \\
\text { buildings } \\
\text { in UR } \\
(\times 1000)\end{array}$ & $\begin{array}{l}\text { Distance } \\
\text { threshold } \\
\text { (meters) }\end{array}$ & $\begin{array}{l}\text { Degree } \\
\text { of the } \\
\text { polyno- } \\
\text { mial }\end{array}$ & Curvature \\
\hline Antwerpen & $\mathrm{Fl}$ & 449 & 123.4 & 6 & -0.11 \\
Brugge & $\mathrm{Fl}$ & 121 & 112.9 & 6 & -0.37 \\
Brussels & $\mathrm{BCR}$ & 705 & 125.7 & 9 & -0.18 \\
Charleroi & $\mathrm{Wal}$ & 255 & 305.4 & 5 & -0.21 \\
Genk & $\mathrm{Fl}$ & 53 & 121.8 & 9 & -0.21 \\
Gent & $\mathrm{Fl}$ & 288 & 116.0 & 6 & -0.12 \\
Hasselt & $\mathrm{Fl}$ & 88 & 109.6 & 8 & -0.18 \\
Kortrijk & $\mathrm{Fl}$ & 96 & 117.3 & 5 & -0.42 \\
Leuven & $\mathrm{Fl}$ & 107 & 112.1 & 9 & -0.22 \\
Liège & $\mathrm{Wal}$ & 348 & 193.5 & 6 & -0.11 \\
Mechelen & $\mathrm{Fl}$ & 82 & 103.6 & 6 & -0.09 \\
Mons & $\mathrm{Wal}$ & 169 & 189.2 & 6 & -0.21 \\
Namur & $\mathrm{Wal}$ & 86 & 329.7 & 5 & -0.24 \\
Oostende & $\mathrm{Fl}$ & 44 & 190.5 & 5 & -0.26 \\
St Niklaas & $\mathrm{Fl}$ & 59 & 76.7 & 8 & -0.14 \\
Tournai & $\mathrm{Wal}$ & 63 & 154.0 & 6 & -0.28 \\
Turnhout & $\mathrm{Fl}$ & 51 & 219.6 & 5 & -0.16 \\
Verviers & $\mathrm{Wal}$ & 46 & 127.7 & 7 & -0.13 \\
\hline
\end{tabular}

BCR: Brussels Capital Region; Fl: Flanders; Wal: Wallonia.

\section{Appendix D}

Dilation curves of the theoretical cities

$$
\text { Fractal cities }
$$

Non fractal cities
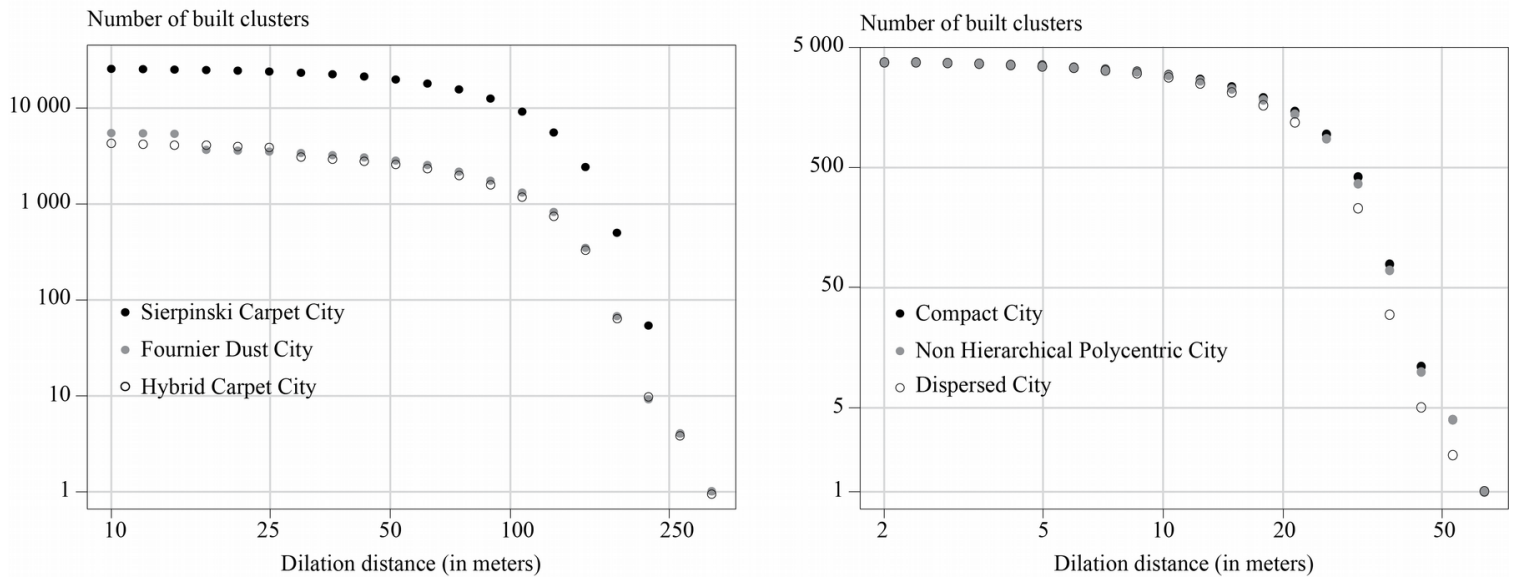


\section{Appendix E}

Empirical and estimated curves for estimating the box-counting dimensions $D_{S}(U R), D_{S}(M A)$, and $D_{B}(M A)$ : Hybrid Carpet City
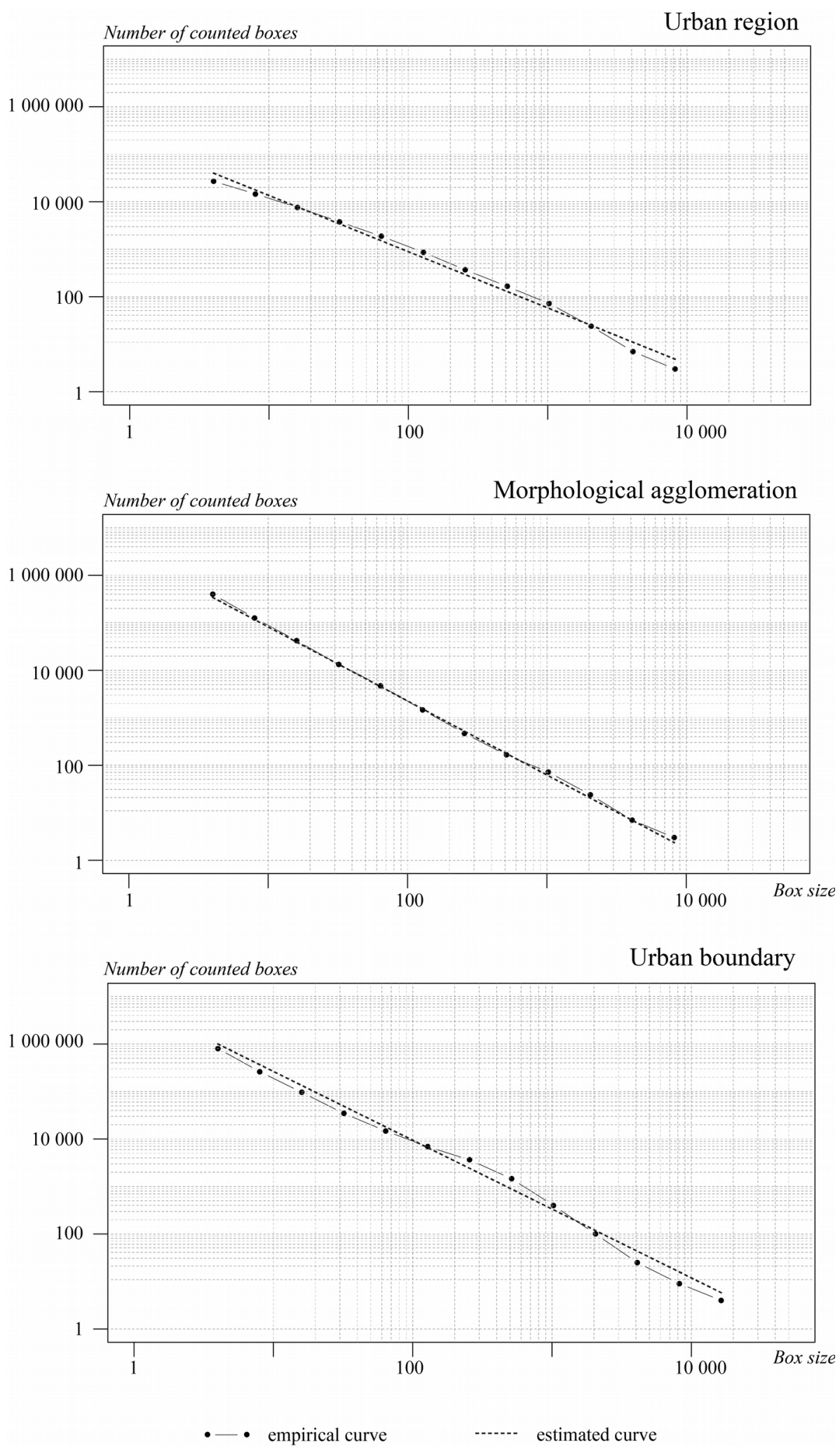


\section{Appendix F}

Empirical and estimated curves for estimating the box-counting dimensions $D_{S}(U R), D_{S}(M A)$, and $D_{B}(M A)$ : Namur
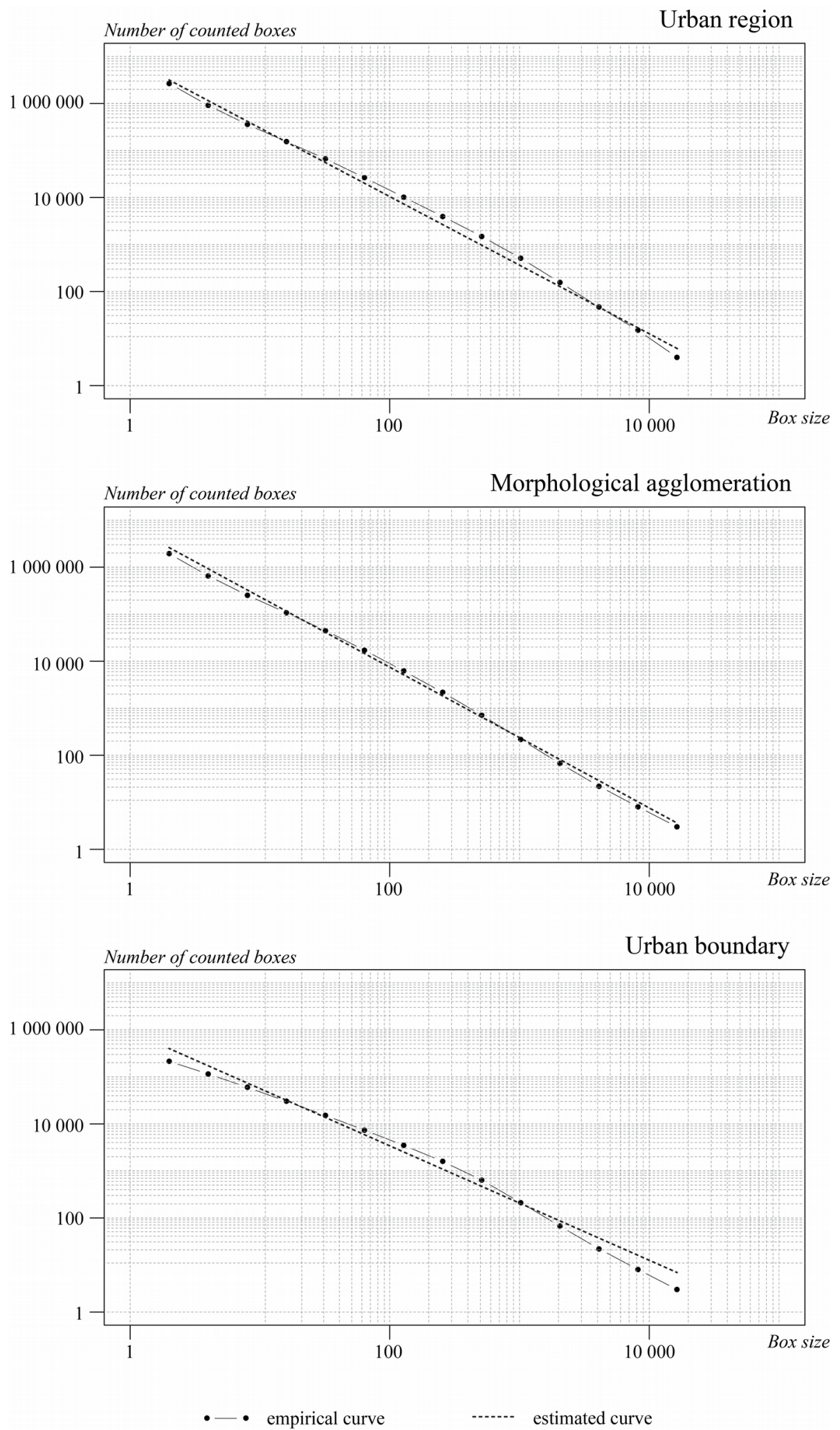


\section{REFERENCES}

Albrechts, L. (2001). Devolution, regional governance and planning systems in Belgium, International Planning Studies, 6(2), 167-182.

Antrop, M. (2004). Landscape change and the urbanization process in Europe, Landscape and Urban Planning, 67(1-4), 9-26.

Batty, M., \& Longley, P. (1994). Fractal Cities, a Geometry of Form and Function, Academic Press, 394 p.

Batty, M., \& Longley, P. (1986). The fractal simulation of urban structure. Environment and Planning A, $18,1143-79$.

Batty, M., \& Longley, P.A. (1987). Urban shapes as fractals, Area 19(3), 215-221.

Batty, M., \& Xie, Y., (1996). Preliminary evidence for a theory of the fractal city, Environment and Planning A, 28, 1745-1762.

Benguigui, L., Czamanski, D., Marinov, M., \& Portugali, Y. (2000). When and where is a city fractal? Environment and Planning B: Planning and Design, 27, 507-519.

Benguigui, L., Blumenfeld-Lieberthal, E., \& Czamanski, D. (2006). The dynamics of the Tel Aviv morphology, Environment and Planning B: Planning and Design, 33, 269-84.

Bogaert, J., Rousseau, R., Van Hecke, P. \& Impens, I. (2000). Alternative area-perimeter ratios for measurement of 2D shape compactness of habitats, Applied Mathematics and Computation, 111, 71-85.

Bosselmann, P. (2008). Urban Transformation: Understanding City Design and Form, Island Press, Washington, DC.

Cavailhès, J., Brossard, T., Foltête, J.-C., Hilal, M., Joly, D., Tourneux, F. P., Tritz, C., \& Wavresky, P. (2009). GIS-based hedonic pricing of landscape, Environmental and Resource Economics, 44(4), 571590.

Cavailhès, J., Frankhauser, P., Peeters, D,. \& Thomas, I. (2004). Where Alonso meets Sierpinski: An urban economic model of a fractal metropolitan area, Environment and Planning A, 36(8), 1471-1498.

Chaudhry, O., \& Mackaness, W. (2008). Automatic identification of urban settlement boundaries for multiple representation databases, Computers, Environment and Urban Systems, 32, 95-109.

Chen, Y. (2011). Derivation of the functional relations between fractal dimension of and shape indices of urban form, Computers, Environment and Urban Systems, 35, 442-451.

Donnay, J., Barnsley, M., \& Longley, P. (2001). Remote Sensing and Urban Analysis. Taylor and Francis, London.

Dujardin, C., Thomas, I., \& Tulkens, H. (2007). Quelles frontières pour Bruxelles? Une mise à jour, Reflets et Perspectives de la Vie Economique XLVI, 156-176.

Feng, J., \& Chen, Y. (2010). Spatiotemporal evolution of urban form and land-use structure in Hangzhou, China: Evidence from fractals, Environment and Planning B: Planning and Design, 37(5), 838-856.

Ferreira, J. A., Condessa, B., Castro e Almeida, J., \& Pinto, P. (2010). Urban settlements delimitation in low-density areas: An application to the municipality of Tomar (Portugal), Landscape and Urban Planning, 97(3), 156-167.

Gonzato, G. (1998). A practical implementation of the box counting algorithm. Computational Geosciences, 24, 95-100.

Imre, A. R., \& Bogaert, J. (2004). The fractal dimension as a measure of the quality of habitat. Acta Biotheoretica, 52(1), 41-56.

Jiang, B., \& Jia, T. (2011), Zipf's law for all the natural cities in the United States: a geospatial perspective. International Journal of Geographical Information Science, 25(8), 1269-1281. 
Longley, P. A., \& Batty, M., (1989). Fractal measurement and line generalization, Computers and Geosciences, 15(2), 167-183.

Lowe, D.G. (1989). Organization of smooth image curves at multiple scales, International Journal of Computer Vision 3, 119-130.

Mandelbrot, B. (1982). The Fractal Geometry of Nature, Freeman: San Francisco

Parr, J. (2007). Spatial definitions of the city: Four perspectives, Urban Studies, 44(2), 381-392.

Richardson, L.F. (1961). A note: measuring compactness as a requirement of legislative apportionment. Mid-west Journal of Political Science, 5, 70-74.

Rozenfeld, H.D., Rybski, D., Andrade, J.S. Jr., Batty, M., Stanley, H.E. \& Makse, H.A. (2008). Laws of population growth, Proceedings of the National Academy of Sciences, 105, 18702-18707.

Shen, G. (2002). Fractal dimension and fractal growth of urbanized areas. International Journal of Geographical Information Science, 16(5), 437-519.

Tannier, C., \& Pumain, D. (2005). Fractals in urban geography: A general outline and an empirical example, Cybergeo, 107, 22p.

Tannier, C., Thomas, I., Vuidel, G., \& Frankhauser, P. (2011). A fractal approach to identifying urban boundaries. Geographical Analysis, 43(2), 211-227.

Thomas, I., Frankhauser, P., \& Badariotti, D. (2012). Comparing the fractality of urban districts: Do national processes matter in Europe? Journal of Geographical Systems, 14(2), 189-208.

Thomas, I., Frankhauser, P., \& De Keersmaecker, M.-L. (2007). Fractal dimension versus density of the built-up surfaces in the periphery of Brussels. Papers in Regional Science, 86(2), 287-307.

Van Criekingen, M., Cornut, P., \& Luyten, S. (2007) Brussels: Polycentricity as images on the map, not in reality. In N. Cattan (Ed), Cities and Networks in Europe: A Critical Approach to Polycentrism (pp 105112). John Libbey Eurotext, Montrouge (France).

Vanneste D., Thomas I., Vanderstraeten L. (2008) The spatial structure(s) of the Belgian housing stock, Journal of Housing and the Built Environment, 23:3, 173-198.

Van Hecke, E., Halleux, J.-M., Decroly, J.-M., \& Mérenne-Schoumacker, B. (2009). Noyaux d'habitat et Régions urbaines dans une Belgique urbanisée, Brussels SPF Economy, P, Monograph No. 9, 205p.

Vandermotten, C., Roelandts, M.G., Halbert, L., \& Cornut, P. (2008). European planning and the polycentric consensus: Wishful thinking?, Regional Studies, 42, 08 (2008) 1205-1217.

Verhetsel, A., Thomas, I., \& Beelen, M. (2010). Commuting in Belgian metropolitan areas: The power of the Alonso-Muth model. Journal of Transport and Land Use, 2(3-4), 109-131

Vuidel, G., Frankhauser, P., \& Tannier, C. (2006). Fractalyse 2.4. freely downloadable software http://fractalyse.org/

Weber, C. (2001). Urban agglomeration delimitation using remote sensing. In J. Donnay, M. Barnsley \& P. Longley (Eds.) Remote Sensing and Urban Analysis (pp.145-159). London, Taylor and Francis. 